\title{
LA INCURSIÓN EN EL CONOCIMIENTO CIENTÍFICO A TRAVÉS DE LA PRUEBA PERICIAL. SU IMPACTO EN LA DECISIÓN JUDICIAL
}

\author{
Ignacio M. Soba Bracesco ${ }^{* *}$
}

\begin{abstract}
RESUMEN
La prueba pericial es uno de los caminos por los cuales habitualmente ingresa el conocimiento científico al Proceso. En el presente trabajo analizaré sus características fundamentales, como por ejemplo, la imparcialidad e idoneidad de los expertos. Se hará referencia a diferentes aspectos de su regulación y diseño en el Derecho comparado, poniendo énfasis en la importancia de las garantías del debido proceso,
\end{abstract}

Fecha Recibido: marzo 31 de 2014 • Fecha Aceptado: julio 2 de 2014

* El presente trabajo es inédito, aunque parte de las ideas y de los conceptos aquí vertidos integran también otros trabajos ya publicados por el autor: SOBA BRACESCO, Ignacio M.: "La prueba pericial y el informe del asesor de parte en el proceso contencioso administrativo de anulación", XVI Jornadas Nacionales de Derecho Procesal (Paysandú-2013), Montevideo, Mastergraf, 2013, pp. 103-118; "La introducción del conocimiento científico al Proceso con énfasis en los denominados procesos de daños-", Revista La Ley Uruguay, Año VI, $\mathrm{N}^{\circ}$ 1, Montevideo-Buenos Aires, La Ley Uruguay, 2013, pp. 29-50; "La responsabilidad de los peritos por su actividad en el proceso: ¿una hipótesis de responsabilidad del Estado?", Revista Crítica de Derecho Privado, No 9, Montevideo-Buenos Aires, La Ley Uruguay, 2012, pp. 695-718.

:*: Doctor en Derecho y Ciencias Sociales. Miembro del Instituto Iberoamericano de Derecho Procesal. Miembro Adherente del Instituto Panamericano de Derecho Procesal. Miembro Fundador de la Asociación Uruguaya de Derecho Procesal Eduardo J. Couture. Integrante del Instituto Uruguayo de Derecho Procesal. Aspirante a Profesor Adscripto de Derecho Procesal I y II de la Facultad de Derecho de la Universidad de la República. Especialista en Derecho de daños, Escuela de Posgrado de la Facultad de Derecho de la Universidad de la República. Abogado en ejercicio e integrante de la Asesoría Jurídica del Banco Central del Uruguay. 
en pos de una más efectiva y transparente tutela de los derechos sustanciales. Finalmente, se destacará la necesidad de controlar la formación, calidad y aceptabilidad del conocimiento extra-jurídico, lo cual le termina por asignar un rol preponderante a la justificación y motivación de las sentencias.

Palabras clave: Prueba pericial, Conocimiento científico, Imparcialidad del perito, Requisitos de idoneidad.

\begin{abstract}
The expert evidence is one of the ways in which scientific knowledge usually enters the trial. This paper relates to its fundamental characteristics, such as impartiality and competence of the experts. I will refer to different aspects of their regulation and design in comparative law, emphasizing the importance of the guarantees of due process, towards a more effective and transparent protection of substantive rights. Finally, we will focus on the need to control the quality and acceptability of extra-legal knowledge, which ends by assigning a key role in motivation and justification of judgments.
\end{abstract}

Key words: Expert evidence, Scientific knowledge, Impartiality of the expert, Suitability requirements.

\title{
1. LA RELACIÓN ENTRE CIENCIA Y PROCESO. UNA APROXIMACIÓN
}

La ciencia tuvo, tiene y tendrá gran relevancia para el Proceso. ${ }^{1}$ Es más, sus vínculos se multiplican rápidamente y hasta se podría decir que aumentan día a día. ${ }^{2}$

A efectos introductorios, se podría entender como ciencia aquel “...conocimiento estructurado en teorías, esto es, en conjunto de hipótesis según las cuales particulares estados de cosas son satisfechos, en grados variables, por modelos que reflejan cierta similitud o unidad" (Cfr. SALVADOR CODERCH, Pablo y RUBÍ PUIG, Antoni, "Riesgos de desarrollo y evaluación judicial del carácter científico de dictámenes periciales”, en Revista InDret, 1/2008, Barcelona, 2008, [http://www.indret.com/pdf/519_es.pdf], p. 23 - consultado el día 27/03/2014. Por su parte, el diccionario de la lengua española, define ciencia -en su primera acepcióncomo: "Conjunto de conocimientos obtenidos mediante la observación y el razonamiento, sistemáticamente estructurados y de los que se deducen principios y leyes generales." Cfr. REAL ACADEMIA ESPAÑOLA: Diccionario de la lengua española, vigésima segunda edición, [http://lema.rae.es/drae/srv/search?id=pfzuSEJWQDXX2DA6StnM], consultado el día 27/03/2014.

2 En ese sentido, expresa TARUFFO que: “...el fenómeno de las pruebas científicas ha tenido -en las últimas décadas- una especie de explosión que plantea problemas nuevos y 
Cada vez más la ciencia incide -a través de la denominada prueba científica- en la dilucidación de distintos asuntos en los que se pretende la obtención de tutela jurisdiccional. La introducción del conocimiento científico al Proceso, así como el correcto uso que se haga del mismo, contribuye a la efectividad de dicha tutela, tanto en los procesos 'individuales' como en los 'colectivos'.

En ese sentido, y para referir tan solo a algunos ejemplos, la ciencia cumple un rol trascendente en la acreditación de la relación o nexo de causalidad en los procesos de responsabilidad civil ${ }^{4}$, la determinación de los denominados riesgos de desarrollo ${ }^{5} \mathrm{o}$ la aplicación del principio precautorio a la problemática de los daños ambientales o de los daños a consumidores ${ }^{6}$.

Refiriéndose a la prueba científica indica el profesor Taruffo que: "En términos generales, con tal expresión se designan los supuestos en que el conocimiento científico es usado en el proceso para aportar el conocimiento

aumenta la importancia de los viejos. En realidad, la frecuencia con que se recurre a la ciencia para suministrar pruebas de los hechos de un caso está creciendo en todos los sistemas procesales...". Cfr. TARUFFO, Michele, La prueba, Madrid, Marcial Pons, 2008, p. 97. Del mismo autor y en similar sentido: Simplemente la verdad. El juez y la construcción de los hechos, Madrid, Marcial Pons, 2010, p. 240.

3 Con la denominación de "procesos colectivos" se hace referencia a aquellos vinculados a la tutela de intereses y/o derechos difusos, colectivos e individuales homogéneos, tal como se prevé en el Código Modelo de Procesos Colectivos para Iberoamérica, elaborado por el Instituto Iberoamericano de Derecho Procesal. INSTITUTO IBEROAMERICANO DE DERECHO PROCESAL, "Código Modelo de Procesos Colectivos para Iberoamérica", XXVI Congreso Colombiano de Derecho Procesal, Bogotá, Universidad Libre, 2005, pp. 1095-1117.

4 Sobre la prueba de la relación de causalidad, entre muchos otros, véase: TARUFFO, Michele, La prueba, Madrid, Marcial Pons, 2008, pp. 251-276.

5 Enseña Mariño López que: “Los riesgos de desarrollo son definidos como los 'causados por un defecto de un producto que no era reconocible a la luz del estado de conocimientos científicos y técnicos existentes en el momento de la comercialización del producto de que se trate.". Cfr. MARIÑO LÓPEZ, Andrés, Los fundamentos de la responsabilidad contractual, Montevideo, Carlos Álvarez Editor, 2005, p. 268.

6 Con relación al principio de precaución o principio precautorio y su aplicación ante los riesgos "desconocidos", sostiene Mirande que: "La función precautoria, al igual que la preventiva, implica la posibilidad de tomar una medida antes de que se produzca un daño. Pero mientras la prevención actúa sobre el riesgo conocido, la precaución actuaría frente a un riesgo desconocido. En virtud de ello, y para evitar la producción de un daño eventual o meramente posible, se intenta dejar de lado la certeza científica que se exige en el paradigma moderno o de la prevención. En la precaución subyace la siguiente idea: si se duda de las conclusiones del conocimiento científico, el derecho de daños no debe depender de ellas de manera absoluta.". Cfr. MIRANDE, Santiago, "Precaver el desarrollo de lo desconocido". Riesgo de desarrollo, información y precaución en el Derecho Uruguayo.", en Revista La Ley Online, Cita Online: D3433/2009. 
o la demostración de un hecho o -mejor dicho- la prueba de la verdad de un enunciado fáctico". ${ }^{7}$

En aquellas cuestiones que se caracterizan, pues, por la necesidad de acudir a otros saberes, como pueden ser aquellos relacionados con la matemática, la física, la química, la bioquímica, la biología, la genética, la ingeniería, la medicina, etc., la complejidad que tienen los hechos a probar exige que se diligencien medios probatorios que de forma apropiada permitan la producción de prueba de tipo científico o, eventualmente, técnico. ${ }^{8}$ Precisamente, en esos casos en los que la acreditación de ciertos enunciados fácticos requiere de conocimientos especialmente calificados, la prueba pericial constituye la vía normal y más adecuada para su incorporación.

Por esa razón, se debe analizar si dicho medio probatorio es capaz de brindar un marco adecuado y fiable para que el conocimiento científico ingrese en el Proceso, respetando adecuadamente las garantías.

Ello hace a lo que denominamos límites a la 'ductilidad' del procedimiento probatorio (y del Proceso en general) ${ }^{9}$, en tanto nos encontramos con una regu-

TARUFFO, Michele, La prueba, Madrid, Marcial Pons, 2008, p. 277.

8 Desde casos aparentemente simples, vinculados por ejemplo a accidentes de tránsito, en los cuales la jurisprudencia tiene la oportunidad de pronunciarse más frecuentemente, hasta otros supuestos más complejos, tales como aquellos derivados de responsabilidad por productos, alimentos, medicamentos, químicos, etc., pasando por otros en los que se discuten aspectos vinculados a la ingeniería civil, naval, química, informática, etc., en todos se requiere el auxilio de la prueba pericial. De forma ilustrativa, para el caso de los accidentes de tránsito, se ha señalado por el Tribunal de Apelaciones en lo Civil de $5^{\circ}$ turno que: “... siendo el punto medular de imputación de responsabilidad a la demandada la velocidad que imprimía su vehículo (...). La prueba requerida en la oportunidad (y no aportada) era, sin lugar a dudas, la pericial. Porque solamente un técnico, estudiando en profundidad los indicios y las características del lugar y de los vehículos puede informar al Oficio la velocidad de los desplazamientos con el grado de certeza requerido." (Cfr. Uruguay, Tribunal de Apelaciones en lo Civil de $5^{\circ}$ Turno: sentencia $n^{\circ}$ 60/2008, de 2 de junio de 2008, Presa -redactor-, Simón, Fiorentino, publicada en Revista Uruguaya de Derecho Procesal, 1-2/2009, Montevideo, FCU, caso 868 , p. 471).

En puridad, la prueba pericial puede ser utilizada para cuestiones no típicamente científicas, sino más bien de índole técnica. Cfr. TARUFFO, Michele, La prueba, Madrid, Marcial Pons, 2008, pp. 277-278. Según Döhring, en los campos muy alejados de la educación y cultura general, no se podrá presuponer que sean conocidos siquiera los conceptos más sencillos de las otras ciencias. Cfr. DÖHRING Erich, La investigación del estado de los hechos en el proceso. La prueba. Su práctica y apreciación, Buenos Aires, Ediciones jurídicas Europa América, 1972, p. 254.

9 La expresión surge luego de la lectura a la obra de ZAGREBELSKY, Il Diritto mitte, que ha sido traducida al español por GASCÓN como El derecho dúctil. Sin embargo se ha justificado dicha traducción señalando algo que no es exactamente lo que aquí se quiere expresar 
lación y un diseño institucional que ofrece, para el ingreso del conocimiento extra-jurídico de tipo técnico o científico, ciertos ámbitos o espacios jurídicamente demarcados. En el presente trabajo se analizarán aspectos que hacen, pues, a características esenciales de la prueba pericial y su concretización, a veces problemática o deficitaria, en la regulación.

Finalmente, como parte de las dificultades que se pueden llegar a plantear en distintos ordenamientos en torno a la producción de estas pruebas, no se podrán dejar de considerar ciertas discusiones que se plantean a nivel de la teoría de la ciencia y del conocimiento ${ }^{10}$, así como aquellos problemas derivados de la propia fiabilidad de la prueba científica, siendo el conocido como caso Daubert -aun a más de veinte años de haberse pronunciado- un famoso hito en la materia. ${ }^{11}$

(véase ZAGREBELSKY, Gustavo, El derecho dúctil, quinta edición, Madrid, Trotta, 2003, p. 19). Buscamos hacer referencia a los límites de la ductilidad entendida como la frontera de lo maleable; esto es, aquello que no se puede traspasar cuando se pretende acudir al conocimiento extra-jurídico para dilucidar el caso concreto.

10 Aun cuando, por lo general, no se asume a nivel jurídico una filosofía de la ciencia específica (la que podría ser, por ejemplo: neoempirista, historicista o sociologista, sintáctica o semántica, inductivista o deductivista, realista, naturalista o antirrealista). Cfr. SALVADOR CODERCH, Pablo y RUBÍ PUIG, Antoni, "Riesgos de desarrollo y evaluación judicial del carácter científico de dictámenes periciales", en Revista InDret, 1/2008, Barcelona, 2008, [http://www.indret. com/pdf/519_es.pdf], p. 22, consultado el día 27/03/2014.

11 EE.UU. Corte Suprema, Daubert vs Merrell Dow Pharmaceuticals, Inc., 509 U.S. 579 (1993). En este caso, “...los demandantes, dos niños pequeños nacidos con malformaciones graves y sus padres alegaban que los daños se debían a que las madres de aquellos habían consumido Bendectin durante el embarazo. El laboratorio demandado negaba la causalidad y, en primera instancia, el Tribunal de Distrito, vistos los peritajes presentados por ambas partes, aplicó el canon de Frye, resolvió que las tesis de los demandantes no cumplían con el requisito de la aceptación general y rechazó su reclamación. La resolución fue confirmada en la apelación y los demandantes recurrieron ante el Tribunal Supremo federal, que aceptó el caso". SALVADOR CODERCH, Pablo y RUBÍ PUIG, Antoni, "Riesgos de desarrollo y evaluación judicial del carácter científico de dictámenes periciales”, en Revista InDret, 1/2008, Barcelona, 2008, [http://www.indret.com/pdf/519_es.pdf], pp. 30-31, consultado el día 27/03/2014. Es muy vasta la bibliografía y la información existente sobre el caso Daubert, tal como lo informan entre otros: TARUFFO, Michele, La prueba, Madrid: Marcial Pons, 2008, pp. 90 a 101 y 277 a 295; DONDI, Angelo, “Paradigmi processuali ed 'expert witness testimony' nel diritto statunitense”, Revista Trimestrale di Diritto e Procedura Civile, Milan, 1996, Dott. A. Giuffrè Editore, pp. 261-285; HARVARD LAW REVIEW, "Admitting doubt: a new standard for scientific evidence”, 123 Harv. L. Rev. 2021 (2010). [http://www.harvardlawreview.org/ media/pdf/vol123_admitting_doubt.pdf]; CORNELL UNIVERSITY LAW SCHOOL, LEGAL INFORMATION INSTITUTE, [http://www.law.cornell.edu/supct/html/92-102.ZS.html], consultados ambos el día 27/03/2014. 


\section{LA REgULACIÓN DE LA PRUEBA PERICIAL}

\subsection{La necesidad de la prueba pericial}

La prueba pericial en el Uruguay se encuentra regulada para los procesos jurisdiccionales, básicamente, en los Códigos actualmente vigentes. ${ }^{12}$ Así, para los procesos civiles (entendidos estos en sentido amplio), se encuentra prevista en los arts. 146 y 177 a 185 del Código General del Proceso ${ }^{13}$, mientras que para los procesos penales, se consagra en los arts. 173 y 187 a 200 del Código del Proceso Penal. ${ }^{14}$

Allí se establece la procedencia de esta prueba, señalándose qué corresponde “... cuando para verificar hechos que interesan al proceso son necesarios conocimientos artísticos, científicos o técnicos especiales" (Uruguay, Código General del Proceso, art. 177; Código Procesal Civil Modelo para Iberoamérica, art. 165), o "... cundo para conocer o apreciar algún hecho o circunstancia pertinente,

12 Sin perjuicio de lo que resulta aplicable al proceso contencioso administrativo de anulación uruguayo, tramitado ante el Tribunal de lo Contencioso Administrativo (TCA), en función de lo dispuesto en los arts. 58 y 104 del decreto ley 15.524, de 9 de enero de 1984. Allí la remisión es a las disposiciones del antiguo Código de Procedimiento Civil uruguayo (CPC) y sus modificativas. En el CPC el "examen pericial” se regulaba por las disposiciones previstas en sus arts. 412 a 430. Véase más ampliamente, SOBA BRACESCO, Ignacio M., "La prueba pericial y el informe del asesor de parte en el proceso contencioso administrativo de anulación", XVI Jornadas Nacionales de Derecho Procesal (Paysandú-2013), Montevideo, Mastergraf, 2013, pp. 103-118.

13 Ver, entre otros, VESCOVI, Enrique (director), DE HEGEDUS, Margarita, KLETT, Selva; CARDINAL, Fernando, SIMÓN, Luis María, PEREIRA CAMPOS, Santiago, Código General del Proceso. Comentado, anotado y concordado, Tomo 5, Buenos Aires, Ábaco, 1998, pp. 270 -375; LANDONI SOSA, Ángel (director), GARDERES, Santiago, GOMES, Fernando, GONZÁlEZ, María Eugenia, VALENTÍN, Gabriel, Código General del Proceso. Comentado, anotado, con jurisprudencia, Vol. 2A, Buenos Aires, BdeF, 2003, pp. 536-568.

14 GARDERES, Santiago, VALENTÍN, Gabriel, con la colaboración de DÍAZ, Soledad, Código del Proceso Penal. Comentado, Montevideo-Buenos Aires, La Ley Uruguay, 2012, pp. 473-490. Cabe consignar que la complejidad de ciertas temáticas especiales, como son aquellas asociadas al fenómeno de la delincuencia organizada, ha determinado que se consagren legislativamente en Uruguay disposiciones como las de la ley 18.914 (promulgada el 22 de junio de 2012 y publicada en el Diario Oficial el 30 de julio de 2012). A modo ilustrativo, sus arts. 2 y 3 refieren al asesoramiento y colaboración que los organismos públicos (e incluso sociedades anónimas en las que participe el Estado) deben brindar a los Juzgados Letrados de Primera Instancia en lo Penal con especialización en Crimen Organizado. Dicha colaboración puede consistir, por ejemplo, en el aporte y facilitación de personal especializado. Se entiende que no se trata necesariamente de peritos, y que habrá que estar al caso concreto para poder determinar si efectivamente se trata prueba procesal penal (como a priori parece que debería ser). 
fueren necesarios o convenientes conocimientos especiales en alguna ciencia, arte o técnica." (Uruguay, Código del Proceso Penal, art. 187).

A nivel internacional, el Derecho comparado ofrece referencias afines. ${ }^{15}$

En Argentina, el Código Procesal Civil y Comercial de la Nación, en su art. 457 establece: "Será admisible la prueba pericial cuando la apreciación de los hechos controvertidos requiere conocimientos especiales en alguna ciencia, arte, industria o actividad técnica especializada.".

En España, la Ley de Enjuiciamiento Civil 1/2000, prevé en su art. 335 numeral 1, que: "Cuando sean necesarios conocimientos científicos, artísticos, técnicos o prácticos para valorar hechos o circunstancias relevantes en el asunto o adquirir certeza sobre ellos, las partes podrán aportar al proceso el dictamen de peritos que posean los conocimientos correspondientes o solicitar, en los casos previstos en esta ley, que se emita dictamen por perito designado por el tribunal.".

Por su parte, en Colombia, el Código General del Proceso (ley 1564 de 2012), en la primera parte de su art. 226 dispone: "La prueba pericial es procedente para verificar hechos que interesen al proceso y requieran especiales conocimientos científicos, técnicos o artísticos.”.

En Estados Unidos de Norteamérica, las Federal Rules of Evidence regulan la prueba proporcionada por "expertos" en las reglas 702 y ss. ${ }^{16}$ Precisamente, la regla 702 “Testimony by Expert Witnesses", establece: "A witness who is qualified as an expert by knowledge, skill, experience, training, or education may testify in the form of an opinion or otherwise if: (a) the expert's scientific, technical, or other specialized knowledge will help the trier of fact to understand the evidence or to determine a fact in issue; (b) the testimony is based on sufficient facts or data; (c) the testimony is the product of reliable principles and

15 Evidentemente, con las referencias que aquí se realiza no se agota el amplio elenco de normas que abordan o regulan, de forma específica o tangencial, la prueba pericial o figuras afines en los sistemas de Derecho comparado (v.gr., pericia de parte, informe del asesor técnico, testigo experto, testigo técnico, etc.). La observación de los ordenamientos extranjeros nos muestra aspectos en los que existen semejanzas y otros en los que predomina la diversidad en las formas de encarar y asumir la problemática de las garantías procesales respecto de la prueba pericial, lo cual abre -en términos de DAMASKA - "un campo inmenso y sorprendente", que incluso puede hacernos "...sentir inseguros acerca de nuestros puntos de referencia básicos.". Cfr. DAMASKA, Mirjan: Las caras de la justicia y el poder del Estado. Análisis comparado del proceso legal, Santiago, Editorial Jurídica de Chile, 2000, p. 9.

16 CORNELL UNIVERSITY LAW SCHOOL - LEGAL INFORMATION INSTITUTE, Federal Rules of Evidence - Rule 702. Testimony by Expert Witnesses, [http://www.law.cornell.edu/ rules/fre/rule_702], consultado el día 27/03/2014. 
methods; and (d) the expert has reliably applied the principles and methods to the facts of the case.".

De allí se desprende que el experto se califica como tal en función del conocimiento, la habilidad, la experiencia, la formación o la educación que posea. Se acude a este tipo de prueba en los casos en que conocimientos especializados científicos, técnicos o de otro tipo del experto puedan ayudar al juez de los hechos para entender la evidencia o determinar un hecho en cuestión. De la regla se extrae, además, que el denominado testigo experto se debe basar en hechos o datos suficientes, métodos y principios fiables, aplicados correctamente a los hechos de la causa. Sobre estos últimos aspectos se profundizará ut infra al referir a la idoneidad y control de adecuación y fiabilidad de la prueba de tipo científico.

En el Reino Unido, las Civil Procedural Rules ${ }^{17}$, en su parte $n^{\circ} 35$ regulan la participación de expertos y asesores en el proceso. Así, la regla 35.1 "Duty to restrict expert evidence", establece que, lo que en un sentido amplio podríamos denominar prueba científica, pericial o prueba a través de expertos, se debe utilizar de manera restrictiva, en aquellos casos en que sea razonablemente requerida para resolver la cuestión a dilucidar en el proceso: "Expert evidence shall be restricted to that which is reasonably required to resolve the proceedings." (La prueba pericial se limitará a lo que sea razonablemente necesario para resolver el procedimiento - traducción no oficial).

A su vez, la regla 35.2 prevé: "Interpretation and definitions.- (1) A reference to an 'expert' in this Part is a reference to a person who has been instructed to give or prepare expert evidence for the purpose of proceedings. (2) 'Single joint expert' means an expert instructed to prepare a report for the court on behalf of two or more of the parties (including the claimant) to the proceedings." (Interpretación y definiciones -. (1) La referencia a un "experto" en esta parte es una referencia a una persona que ha sido instruido para dar o preparar la prueba pericial de los efectos del procedimiento. (2) "experto único" un experto encargado de preparar un informe para la corte en nombre de dos o más de las partes (incluyendo el demandante) en el procedimiento - traducción no oficial).

Por último, pero no por ello menos importante, se destaca la regla 35.3 "Experts - overriding duty to the court", la cual dispone: "(1) It is the duty of experts to help the court on matters within their expertise. (2) This duty overrides any obligation to the person from whom experts have received instructions or by whom they are paid." De allí se extrae que los expertos tienen el "deber" fundamental de ayudar a la corte sobre cuestiones de su competencia, y que

17 MINISTRY OF JUSTICE, Civil Procedural Rules - Part 35 Experts and Assessors, [http:// www.justice.gov.uk/courts/procedure-rules/civil/rules/part35], consultado el día 27/03/2014. 
dicho derecho prevalece sobre cualquier obligación de la persona de la que los expertos han recibido instrucciones o por quién se les paga.

Si bien las regulaciones en Derecho comparado y, en particular, en el common law presentan diferencias importantes con el civil law, su análisis aunque sea somero sirve para comprender y comprobar que en ambos casos se comparte la necesidad de contar con herramientas fiables y adecuadas que hacen a la incorporación del conocimiento extra-jurídico en el proceso. Se trata de intentar dar respuestas a interrogantes fácticas mediante la mejor ciencia que los tribunales puedan conseguir. ${ }^{18}$

La singularidad con la que está dotada la prueba científica, y por supuesto la pericial, refiere a un campo muy sensible para el derecho, el de la incorporación de otros 'saberes' y conocimientos, de nuevas técnicas y métodos, de la vinculación interdisciplinaria necesaria para la elaboración de herramientas útiles para la dilucidación de los diversos problemas que se someten al debate jurisdiccional.

Esto significa que, en el plano del conocimiento, la ciencia del perito es su ciencia y no la del Juez. El Juez no es omniscio, hay una brecha, un límite para el conocimiento, el cual es admitido en la propia legislación procesal desde que se prevé la procedencia de la prueba pericial en función de la necesariedad para el proceso de un conocimiento que no es jurídico. Hay hechos que interesan al proceso, hechos controvertidos, que para ser probados requieren -necesariamente- conocimientos especiales. ${ }^{19}$ De esa forma se supera el plano de la conveniencia para pasar al de la necesidad de los conocimientos que el Juez no posee. Es imprescindible poseer los conocimientos especializados para comprender a los hechos en su verdadera significación. ${ }^{20}$

En efecto, los Jueces, de regla, no se capacitan, ni tienen que hacerlo, en las diferentes especializaciones de la medicina, la biología, la química molecular, la genética, etc. En caso de no poder recurrir a estos otros ámbitos del conocimiento el Juez no podría fundamentar o motivar correctamente su decisión, pudiendo incluso caer en la arbitrariedad por la falta de una adecuada comprensión del fenómeno científico que forma parte del caso.

18 MOORE, Michael S., Causalidad y responsabilidad. Un ensayo sobre derecho, moral y metafisica, Madrid, Marcial Pons, 2011, p. 140.

19 Cfr. PARRA QUIJANO, Jairo, Manual de derecho probatorio, Bogotá, Ediciones Librería del profesional, décimo tercera edición, 2002, p. 533.

20 Entre otros, LANDONI SOSA, Ángel, "La prueba pericial con especial referencia al proceso civil”, en IX Jornadas Nacionales de Derecho Procesal (Rivera-1997), Montevideo, Editorial Universidad, 1997, p. 219. 
Dicha especificidad y necesariedad conlleva, por su parte, la insustituibilidad de la prueba. ${ }^{21}$

Lejos estamos de considerar que se pueda sustituir este conocimiento necesario por la construcción de razonamientos judiciales basados en el sentido común o la experiencia. ${ }^{22}$

Por esa razón, y como fue planteado desde un inicio, se debe analizar si la prueba científica de tipo pericial es capaz de brindar un marco adecuado y fiable para que el conocimiento extra-jurídico ingrese en el Proceso, respetando adecuadamente las garantías procesales.

\subsection{El perito o experto como sujeto del proceso}

El perito es, o debería ser, un experto o especialista. En el ordenamiento uruguayo se califica al perito como un auxiliar del tribunal, ajeno a los intereses particulares de las partes. Al menos en nuestro país, no se vincula a este instituto el informe técnico emanado del denominado 'perito de parte` ${ }^{23}$

${ }^{21} \quad$ Ahora bien, sin perjuicio que luego se volverá sobre el punto, se debe destacar que en el plano de su aplicación procesal si bien estamos ante conocimientos necesarios, no estamos ante conocimientos que - una vez vertidos al proceso- se transformen automáticamente en obligatorios o decisorios (Uruguay - Código General del Proceso, art. 184; Código Procesal Civil Modelo para Iberoamérica, art.172). Respecto de la sustitución o 'canjeabilidad' de medios probatorios, en Uruguay, la nueva redacción dada al Código General del Proceso por ley 19.090 de 14 de junio de 2013, prevé en su art. 144 ordinal segundo que se “...rechazará el diligenciamiento del medio que manifiestamente tienda a sustituir a otro que específicamente corresponda por la ley o por la naturaleza del hecho a probar, en cuyo caso el tribunal podrá disponer el diligenciamiento del medio de prueba que correspondiere.".

22 Considero con TARUFFO que se debe actuar de modo especialmente cauto cuando se acude a esas $\mathrm{u}$ otras nociones similares, pues no se trata de un conjunto claro, coherente y homogéneo de criterios de razonamiento. La utilización del sentido común, por ejemplo, plantea dudas incluso desde el punto de vista epistemológico. Precisamente, cuando el profesor italiano refiere a los background knowledges -"cultura de hombre medio", "máximas de la experiencia”- señala que dichas nociones “...no son controladas científicamente, y son frecuentemente inaceptables o fruto de errores y prejuicios consolidados en el sentido común, de tal manera que pueden representar una guía al error, más que una ayuda en la búsqueda de la verdad.". Por ese y otros motivos es que se deberían encender señales de alerta cuando los abogados y los jueces refieren al sentido común o a la experiencia para señalar que se tiene por acreditadas ciertas hipótesis de hecho o enunciados fácticos. TARUFFO, M., Sobre las fronteras. Escritos sobre la justicia civil, Bogotá, Temis, 2006, pp. 117-118 y pp. 190-191. Además, véase del mismo autor, La prueba, Madrid, Marcial Pons, 2008, pp. 267-271.

23 LANDONI SOSA, Ángel (director), GARDERES, Santiago, GOMES, Fernando, GONZÁLEZ, María Eugenia, VALENTÍN, Gabriel, Código General del Proceso. Comentado, anotado, con jurisprudencia, Vol. 2A, Montevideo-Buenos Aires, BdeF, 2003, p. 537. Respecto de los 
Más precisamente, en la teoría general del proceso, dentro del tema más amplio de los sujetos del proceso, se encuentra el relativo al tribunal que debe intervenir en el mismo, así como a sus auxiliares (también denominados como sujetos "accesorios", distintos de los sujetos "principales" del proceso). ${ }^{24}$

En ese sentido, "El perito es un auxiliar del tribunal, ajeno a los intereses particulares de las partes, que tiene por función suministrar al juez argumentos o razones para la formación de su convencimiento respecto de esos hechos,

procesos judiciales, como señalan CARDINAL y KLETT, en Uruguay el Código General del Proceso refiere a 'asesores técnicos' de las partes en los arts. 181 y 187 (i.e., en la correlación que habitualmente se hace, aunque sin quizás coincidir exactamente en su texto, arts. 169 y 175 del Código Procesal Civil Modelo para Iberoamérica), para indicar que tanto en la práctica de las pericias como de las inspecciones judiciales las partes podrán concurrir con sus abogados y asesores técnicos quienes, incluso, podrán formular observaciones de las que se dejará constancia en acta. CARDINAL, Fernando, KLETT, Selva, "El informe del asesor técnico de la parte: su naturaleza jurídica y valoración”, en IX Jornadas Nacionales de Derecho Procesal (Rivera-1997), Montevideo, Editorial Universidad, 1997, pp. 209-217. Es que, como lo expresa con claridad PARRA QUIJANO, el asesoramiento de las partes por expertos "Es aconsejable, en los procesos en los que el dictamen pericial es difícil y definitivo para el despacho de las pretensiones o de las excepciones, recurrir a esta clase de asesor...". Esto, a su vez, resulta importante para la valoración del propio dictamen, pues si las partes asesoradas por los expertos presentan a su vez sus conclusiones y críticas a la pericia, esto “...le permitirá al juez escudriñarla en mejor forma.”. Cfr. PARRA QUIJANO, Jairo, Manual de Derecho Probatorio, decimotercera edición, ampliada y actualizada, Bogotá, Librería del Profesional, 2002, pp. 544 y p. 553.

24 Con BARRIOS DE ANGELIS se puede decir que sujeto del proceso es "toda persona que, implicada (aunque no sea más que accidentalmente) en su objeto, produce los actos o recibe los efectos de dicho proceso" (Cfr. BARRIOS DE ÁNGELIS, Dante, El proceso civil, Montevideo, Idea, 1989, p. 61) o -con más detalle- que: "Son sujetos del proceso quienes lo hacen y aquellos para quienes se hace. Es decir, aquellas personas físicas o jurídicas que producen los actos del proceso, así como -esos mismos u otros- que por su vínculo especial con el objeto, dan lugar al proceso y sufren o aprovechan de modo inmediato, de las modificaciones del objeto. Todo sujeto del proceso se caracteriza por su implicación en el objeto, por un determinado plexo de situaciones jurídicas y por la participación funcional correspondiente." (Cfr. Barrios De Ángelis, Dante, Teoría del Proceso, segunda edición actualizada (reimpresión), Montevideo-Buenos Aires, BdeF, 2005, p. 93). Con estas definiciones, se abarca a los denominados sujetos principales -tribunal, partes, tercerosy a los llamados sujetos accesorios -en general, auxiliares del tribunal o de las partes (LANDONI SOSA, Ángel (director); GOMES, Fernando; VALENTÍN, Gabriel; GARDERES, Santiago y GONZÁlEZ, María Eugenia, Código General del Proceso. Comentado, anotado, con jurisprudencia, Vol. 1, Montevideo-Buenos Aires, BdeF, 2002, p. 39). GELSI BIDART los incluye en la categoría de "sujetos complementarios o secundarios, o relativamente accidentales o accesorios, o no universales -en cuanto no concurren necesariamente en todo proceso". Cfr. GELSI BIDART, Adolfo, "Significación de la pericia como instituto procesal", Revista Judicatura, № 33, Montevideo, 1992, pp. 19-20. 
con base en sus conocimientos científicos, artísticos o técnicos, en el marco del correspondiente encargo judicial". 25

Devis Echandía indica que: "Consideran que el perito es un auxiliar del juez, entre otros, Carnelutti, Florian quien también los denomina órganos de la ejecución, Franchi, Bonnier, Santiago Sentís Melendo quien los llama asesores del juez y auxiliares de la justicia, Valentín Silva Melero quien considera que "hay que destacar la actividad pericial como auxilio o colaboración del juez", Louis Mallard y René Morel quienes lo consideran un auxiliar de la justicia, encargado temporalmente de un servicio público, Paul Julien Doll para quien son auxiliares de la justicia, Antonio Rocha, Moacyr Amaral Santos Y Aragoneses-Viada.”. ${ }^{26}$ Así también, el propio maestro Devis Echandía señala que el perito es, indudablemente, “...un auxiliar o colaborador técnico del juez y de la justicia". ${ }^{27}$

También se ha señalado que: "La designación judicial representa, además, una garantía de imparcialidad o de idoneidad del perito" ${ }^{28}$, lo que será analizado infra con más detalle y cuidado por las razones que se expondrán. Es que se entiende que la designación judicial de los peritos no es - per se- una garantía de imparcialidad e idoneidad de los mismos.

\subsection{La imparcialidad e idoneidad del perito}

Respecto de la imparcialidad, en primer lugar, se advierte que no siempre su designación judicial -imparcialidad jurídica del perito mediante- será una garantía de su 'imparcialidad' científica, técnica o artística, pues, sin perjuicio de su no vinculación con las partes, se puede tratar de peritos que se encuentren 'afiliados' a cierta corriente o posición doctrinaria o académica que no les permita abstraerse totalmente de la misma, repercutiendo ello en

25 LANDONI SOSA, Ángel (director), GARDERES, Santiago, GOMES, Fernando, GONZÁLEZ, María Eugenia, VALENTÍN, Gabriel, Código General del Proceso. Comentado, anotado, con jurisprudencia, Vol. 2A, Montevideo-Buenos Aires, BdeF, 2003, p. 537.

26 DEVIS ECHANDÍA, Hernando, Teoría general de la prueba judicial, Tomo II, quinta edición, Buenos Aires. Víctor P. de Zavalía-Editor, 1981, pp. 309-310.

$27 \quad$ Ibidem., pp. 311 y 319.

28 LANDONI SOSA, Ángel (director), GARDERES, Santiago, GOMES, Fernando, GONZÁLEZ, María Eugenia, VALENTÍN, Gabriel, Código General del Proceso. Comentado, anotado, con jurisprudencia, Vol. 2A, Montevideo-Buenos Aires, BdeF, 2003, p. 539. En Argentina MÜLLER ha referido como requisito esencial de designación del perito, el de su idoneidad respaldada por título habilitante y por su trayectoria. MÜLLER, Enrique C., "La prueba del daño ecológico", en Revista La Ley Online, Cita Online: D2676/2010. 
sus conclusiones para el caso concreto. Los mecanismos legales de excusación y recusación se presentan, de esa manera, como herramientas de utilidad que no se deben descuidar en la práctica, y que se podrían adaptar para también ser utilizados en estos casos.

En el ámbito del proceso civil, el art. 179 del Código General del Proceso uruguayo, relativo a impedimentos y recusaciones de peritos, remite a las causales previstas para los jueces, las que se encuentran establecidas en los arts. 325 y siguientes de dicho Código. A saber: "Será causa de recusación toda circunstancia comprobable que pueda afectar la imparcialidad del Juez por interés en el proceso en que interviene o afecto o enemistad en relación a las partes o a sus abogados y procuradores, así como por haber dado opinión concreta sobre la cuestión sometida a su decisión (prejuzgamiento)”. ${ }^{29}$

En España, el art. 335 de la Ley de Enjuiciamiento Civil 1/2000, de 7 de enero de 2000, prevé: "Objeto y finalidad del dictamen de peritos. Juramento o promesa de actuar con objetividad. (...) 2. Al emitir el dictamen, todo perito deberá manifestar, bajo juramento o promesa de decir verdad, que ha actuado y, en su caso, actuará con la mayor objetividad posible, tomando en consideración tanto lo que pueda favorecer como lo que sea susceptible de causar perjuicio a cualquiera de las partes, y que conoce las sanciones penales en las que podría incurrir si incumpliere su deber como perito". ${ }^{30}$ Luego, el art. 343 refiere al instituto de las tachas de los peritos.

Por su parte, en Colombia, el Código General de Proceso dispone, en su art. 226 -en lo pertinente- que: “...El perito deberá manifestar bajo juramento que se entiende prestado por la firma del dictamen que su opinión es independiente y corresponde a su real convicción profesional. El dictamen deberá acompañarse de los documentos que le sirven de fundamento y de aquellos que acrediten la idoneidad y la experiencia del perito...". A su vez, en el art. 235 de dicho Código se hace referencia expresa a la imparcialidad y objetividad del perito. De conformidad con la sana crítica se podrá negarle efectos al dictamen cuando existan circunstancias que afecten gravemente su credibilidad (aspecto éste que se retomará en el capítulo siguiente).

29 En Argentina, el Código Procesal Civil y Comercial de la Nación dispone en su art. 466 que: "Son causas de recusación del perito las previstas respecto de los jueces; también, la falta de título o incompetencia en la materia de que se trate...".

30 En España, MONTERO AROCA analiza la abstención y recusación de los peritos haciendo referencia a la imparcialidad de los mismos, en el sentido de que “...su dictamen ha de estar determinado sólo por el cumplimiento correcto de la función...”. Cfr. MONTERO AROCA, Juan, La prueba en el proceso civil, 5ª edición, Pamplona, Thomson Civitas, 2007, p. 362. 
Esto es particularmente relevante, y así se ha entendido por algunos magistrados. Por ejemplo, Castro ha señalado que: "Como destaca Taruffo, 'existe una conexión directa entre imparcialidad y verdad' de modo que la imparcialidad no es sólo una exigencia ética sino también una condición epistemológica para buscar la verdad con la mayor objetividad. ${ }^{31}$ Pero sobre todo, no hay que olvidar que la función de la prueba pericial es ofrecer al juez la información técnica y científica para juzgar, nunca sustituirlo en la decisión. La reconstrucción de los hechos del caso debe ser hecha por el juez sobre la base del examen del conjunto de los medios probatorios aportados a la causa, analizados con criterios de sana crítica, de modo que la pericia no constituye una prueba que excluya la consideración de otras que -como en este caso- puedan conducir a un resultado diverso (MORELLO, Augusto. "la prueba pericial y su evaluación” en Judicatura $n^{\circ} 33$ p. 12; TARUFFO, M. la prueba. Madrid, 2008, p. 90 y 131)". ${ }^{32}$

La idoneidad, por su parte, se encuentra estrechamente relacionada con la cuestión de la fiabilidad del peritaje (aspecto sobre el cual se volverá en el apartado siguiente). Además, el valorar la especialidad técnica o científica de los peritos puede ser de gran dificultad para el tribunal, pues los propios parámetros para distinguir una especialidad de otra pueden constituir un tema en sí mismo ajeno a lo estrictamente jurídico. ${ }^{33}$

Por cierto que no se pretende que el órgano jurisdiccional se transforme en científico - lo que evidentemente sería imposible- y mucho menos que repita los análisis y experimentos que conforman la propia prueba científica.

31 Cfr. TARUFFO, Michele. Simplemente la verdad. El juez y la construcción de los hechos. Madrid, 2010, p. 138

32 Uruguay, Tribunal de Apelaciones en lo Civil de $1^{\circ}$ Turno: sentencia n 34/2012, de 21 de marzo, Vázquez -redactor-, Salvo, Castro - discorde-.

33 En Uruguay, el Tribunal de lo Contencioso Administrativo, en sentencia n ${ }^{\circ}$ 612/2012, de 27 de septiembre de 2012 (Preza, Harriague, Sassón, Gómez Tedeschi -redactor-, Tobía) señala: "Es de toda evidencia que, cada diferente campo pericial suele estar relacionado con una determinada profesión u oficio, pues una persona es perita en aquellas parcelas de la ciencia, arte o práctica que conoce, ya sea porque es conocida su experiencia en tales asuntos, ya sea porque ostenta un título de estudios que le acreditan de un modo oficial ciertos conocimientos (ingeniero, arquitecto, médico, etc.)". En Argentina, por su parte, el art. 459 del Código Procesal Civil y Comercial de la Nación expresamente aclara que al ofrecer la prueba pericial se indicará la especialización que ha de tener el perito. En España, el art. 340 ordinal 1 establece -en lo vinculado con la especialidad- que los peritos deberán poseer el título oficial que corresponda a la materia objeto del dictamen y a la naturaleza de éste. Si se tratare de materias que no estén comprendidas en títulos profesionales oficiales, habrán de ser nombrados entre personas entendidas en aquellas materias". 
Lo que se exige, siguiendo a TARUFFO, “...es que el juez sea capaz de valorar si está en el ámbito de una forma de conocimiento dotada de dignidad y validez científica, y si los métodos de investigación y control típicos de esa ciencia han sido correctamente aplicados en el caso particular que debe juzgar.". ${ }^{34}$ Por ello es que se requiere situar o contextualizar al peritaje, estableciendo el lugar de donde el perito extrae sus conocimientos $y$, porque no, indicando si pertenece a una determinada comunidad científica, detallando lo que son sus méritos académicos, científicos, técnicos, etc. ${ }^{35}$

Otro obstáculo, estrechamente vinculado al anterior es el de la (in)existencia de peritos con la especialidad técnica o científica suficiente como para analizar los complejos entramados técnicos o científicos que componen la actuación objeto del proceso y de la prueba en ciertos casos. Quizás los problemas que enfrenta la introducción al proceso del conocimiento especializado extra-jurídico, de tipo técnico-científico, sea la explicación por la cual hoy en día todavía nos encontramos ante un manejo un tanto aficionado respecto de temas que deberían ser resueltos de otro modo.

A veces, la prueba pericial de calidad es de alto costo para los litigantes ocasionales, o en el medio judicial no se cuenta con los especialistas adecuados que permitan ilustrar al Juez y a las partes acerca de determinados hechos, o una combinación de esos y otros factores que hacen que, a pesar que los especialistas existen, estos no apetecen la "invitación” (el encargo) a participar en el proceso. Por todo esto, uno de los principales desafíos que se exhiben en la construcción de la decisión judicial sobre cuestiones en las que incide el conocimiento especializado es la designación de los propios peritos en el discurrir del proceso.

Evidentemente, las dificultades prácticas tienden a consolidarse pues la selección de los peritos se realiza casi exclusivamente entre aquellos que aceptan las reglas de juego, encontrándose -como lo ha destacado lúcidamente Damaska- “...habituados a la rutina judicial-burocrática...”. ${ }^{36}$ Como

34 TARUFFO, Michele, La prueba, Madrid, Marcial Pons, 2008, p. 294.

35 Cfr. SOBA BRACESCO, Ignacio M., "La introducción del conocimiento científico al Proceso -con énfasis en los denominados procesos de daños-”, Revista La Ley Uruguay, Año VI, $\mathrm{N}^{\circ}$ 1, Montevideo-Buenos Aires, La Ley Uruguay, 2013, pp. 29-50; "La prueba pericial y el informe del asesor de parte en el proceso contencioso administrativo de anulación”, XVI Jornadas Nacionales de Derecho Procesal (Paysandú-2013), Montevideo, Mastergraf, 2013, pp. 103-118.

36 DAMASKA, Mirjan, Las caras de la justicia y el poder del Estado. Análisis comparado del proceso legal, Santiago, Editorial Jurídica de Chile, 2000, p. 97. 
se adelantara al inicio, la dimensión de estos y otros problemas que afronta la prueba pericial se encuentran vinculados con lo que es su regulación y diseño desde el punto de vista jurídico.

Es más, puede suceder que los únicos especialistas en una determinada materia sean los propios funcionarios de la administración demandada en el caso concreto. Se trata de un tema a sopesar por el tribunal (no sólo al momento de la valoración), ${ }^{37}$ para no diligenciar pericias que luego carezcan de utilidad a los efectos del proceso. ${ }^{38}$

$37 \quad \mathrm{Al}$ decir de DÖHRING sobre la limitación del perito a las cuestiones atinentes a su especialidad: "A veces, el experto cree cándidamente que puede emitir juicios igualmente certeros en otros terrenos, aunque no tenga pericia en ellos. Eso ocurre, por ejemplo, cuando un médico, luego de describir los daños que una persona ha sufrido en la salud a consecuencia de un accidente, asignándoles un grado, se pronuncia luego con gran firmeza sobre la futura disminución de la capacidad adquisitiva de la víctima, olvidando que esa capacidad dependerá igualmente de la situación del mercado de trabajo y de otras circunstancias ajenas a la ciencia médica.". DÖHRING, Erich, La investigación del estado de los hechos en el proceso. La prueba. Su práctica y apreciación, Buenos Aires, Ediciones Jurídicas Europa-América, 1972, p. 260. TARUFFO, por su parte, también indica que la designación del perito por el juez no garantiza que este tenga una preparación técnicocientífica suficientemente adecuada para el caso. Las modalidades con las que se realiza la inscripción de los peritos en los listados no asegura un nivel particularmente adecuado de preparación profesional. Cfr. TARUFFO, Michele, Simplemente la verdad. El juez y la construcción de los hechos, Madrid, Marcial Pons, 2010, p. 244.

38 En un caso en el que se procesó un acto administrativo vinculado a la concesión de líneas de transporte terrestre de pasajeros, y en el cual el actor se opone a la agregación de informes solicitados a un Grupo Técnico Asesor del Ministerio de Transporte y Obras Públicas y al Ministerio de Trabajo y Seguridad Social, argumentando que: “...en cuanto al solicitarse opiniones de orden técnico, se estaría sustituyendo a la prueba pericial sin las debidas garantías ya que se trata de órganos que forman parte del Estado, demandado en autos.”, el TCA consideró que no se está ante un supuesto de prueba pericial “...sino que se trata de un informe solicitado a órganos que tuvieron injerencia en el dictado del acto impugnado. No tratándose de un medio probatorio prohibido por la ley, dilatorio o impertinente, (art. 74 del Dec. Ley - 15.524), se desestimará la oposición deducida, sin perjuicio de lo que pueda resultar en cuanto a la admisibilidad de dicha prueba en oportunidad de dictarse sentencia.". Cfr. Uruguay, Tribunal de lo Contencioso Administrativo: sentencia n 1358/1992, de 30 de setiembre de 1992, Pereira Núñez de Balestrino, Galagorri, Díaz Romeu. En otra oportunidad, dicho Tribunal rechazó el diligenciamiento de un oficio solicitado por la administración y dirigido a uno de sus propios servicios, señalando que: “...la parte no puede oficiarse a sí misma, ni a sus reparticiones y a que no puede solicitar que se diligencie por oficios una prueba que pudo obtener por otros medios, conforme al principio general recogido por el art. 190 del Código General del Proceso". Cfr. Tribunal de lo Contencioso Administrativo: sentencia n ${ }^{\circ}$ 999/2011, de 22 de noviembre de 2011, Monserrat, Harriague, Sassón, entre otras. 
En definitiva, el control de la idoneidad impone situar o contextualizar al peritaje dentro de su especialidad, estableciendo el lugar de donde el perito extrae sus conocimientos y, porque no, indicando si pertenece a una determinada comunidad científica, detallando lo que son sus méritos académicos, científicos, técnicos, etc. ${ }^{39}$

\section{Algunos aportes de teoría de la Ciencia. ANÁlisis DE FIABILIDAD Y VALORACIÓN DE LA PRUEBA}

Continuando con lo expuesto, se puede señalar que la perspectiva 'clásica' de estudio de la prueba pericial podría quizás cambiar si, por ejemplo, se tomara en consideración la visión de Kuhn sobre la ciencia.

Habría que analizar si lo que se produce en un proceso como prueba científica proviene de una determinada comunidad científica operando dentro de un paradigma $x$, practicando lo que se denomina ciencia normal o, si por el contrario, es fruto de la actuación de científicos que propugnan y adhieren a un nuevo paradigma. Es que la ciencia progresa, según Kuhn, mediante un esquema que esencialmente podría ser descripto de la siguiente manera: preciencia ciencia normal - crisis - revolución - nueva ciencia normal - nueva crisis. ${ }^{40}$

39 SOZZO y BERROS afirman, por ejemplo, que: “...no se ha dado debida cuenta dentro del campo jurídico del carácter parlamentario que asumen las ciencias ante cuestiones complejas en las que campea un marco de incerteza o controversia científica y de qué modo canalizarlo en la regulación de las pericias. Actualmente, no hay obligación alguna por parte de los peritos de presentar un "cuadro controversial" completo, en el cual se dé cuenta de las diversas posturas respecto del problema analizado así como, tampoco, de la posición que ellos asumen para sí. De este modo, la parlamentariedad científica, no es advertida por la normativa que regula las pericias. No se considera que pueda un juez apartarse de la pericia en razón de considerar el panorama completo de producción de conocimiento que arroje un esquema de controversia o incerteza científica, respecto del tema que llega a su conocimiento. Por el contrario, la forma de relacionamiento que guarda el conocimiento experto con el juez o tribunal, puede ser adscripta a la idea moderna de que el derecho constituye un modo de conocimiento reflejo. Una deconstrucción de este tipo de articulación entre pericias y decisión judicial exige dar cuenta del modo contemporáneo de producción del conocimiento para poder luego sí repensar la regulación del trabajo experto en el proceso y más en general rever el modo de relación que en el marco del proceso judicial se entabla entre conocimiento experto y saber legal, de modo de permitir garantizar la autonomía de ambos y el posterior debate democrático sobre la decisión." (énfasis agregado). SOZZO, Gonzalo, BERROS, María Valeria: "Una agenda para el principio precautorio", Revista La Ley Online, Cita Online: D3440/2009.

40 CHALMERS, Alan F., ¿Qué es esa cosa llamada ciencia?, Madrid, Siglo XXI, decimosexta edición, 1994, p. 128. Naturalmente, la perspectiva de KUHN sobre la teoría del conocimiento no es la única, pero resulta de utilidad para indicar a los efectos de esta obra la fragilidad 
Como señala Chalmers analizando los paradigmas de Kuhn: "Una ciencia madura está regida por un solo paradigma. El paradigma establece las normas necesarias para legitimar el trabajo dentro de la ciencia que rige. Coordina y dirige la actividad de -resolver problemas- que efectúan los científicos normales que trabajan dentro de él. La característica que distingue a la ciencia de la no ciencia es, según Kuhn, la existencia de un paradigma capaz de apoyar una tradición de ciencia normal". ${ }^{41}$

Ahora bien, aun luego de identificar los preconceptos con los que el científico trabaja, se deberá reconocer que no siempre en sus resultados se llega a la "verdad". Estamos ante enormes problemas que se afrontan no sólo ante la dificultad de definir "verdad", sino también por las dificultades que implica encontrarla en la realidad, siendo que -la gran mayoría de las veces- sólo resta un conocimiento probable de ella. ${ }^{42}$

Como forma de acercarnos al problema en el plano del Derecho, se podría acudir, para un mayor conocimiento acerca de cómo opera la prueba científica, al análisis de fiabilidad del método empleado en cada caso concreto y, por otro lado, al análisis de fiabilidad de sus resultados. Esto es, la apreciación acerca de

que puede presentar el terreno científico, y cómo ello puede impactar en lo jurídico. KUHN distingue “...dos tipos de desarrollo científico: normal y revolucionario. La mayor parte de la investigación científica que tiene éxito produce como resultado un cambio del primer tipo (...). Pero el desarrollo científico manifiesta también una modalidad no acumulativa, y los episodios que la exhiben proporcionan claves únicas de un aspecto central del conocimiento científico. (...). Los cambios revolucionarios son diferentes y bastante más problemáticos. Ponen en juego descubrimientos que no pueden acomodarse dentro de los conceptos que eran habituales antes de que se hicieran dichos descubrimientos...”. Cfr. KUHN, Thomas S., El camino desde la estructura. Ensayos filosóficos 1970-1993, CONANT, James y HAUGELAND, John (compiladores), Barcelona, Paidós, 2002, p. 23 y p. 25.

${ }^{41}$ CHALMERS, Alan F., ¿Qué es esa cosa llamada ciencia?, Madrid, Siglo XXI, decimosexta edición, 1994, p. 129.

42 Sobre la prueba y la verdad, relación que despierta mucho interés en la dogmática procesal (al punto que, incluso, se ha visto reflejado en las regulaciones procesales, por ejemplo, en los arts. $24 \mathrm{n}^{\circ} 4$ o 25.2 del Código General del Proceso uruguayo y arts. 33 n4 y 34.2 del Código Procesal Civil Modelo para Iberoamérica), se pueden consultar -entre muchos otros- los trabajos de: DEVIS ECHANDÍA, Hernando, Teoría general de la prueba judicial, Tomo I, quinta edición, Buenos Aires. Víctor P. de Zavalía-Editor, 1981, pp. 254-256; PARRA QUIJANO, Jairo, Manual de Derecho Probatorio, decimotercera edición, ampliada y actualizada, Bogotá, Librería del Profesional, 2002, pp. 147-158; TARUFFO, Michele, La prueba, Madrid, Marcial Pons, 2008, pp. 15-35 y Simplemente la verdad. El juez y la construcción de los hechos, Madrid, Marcial Pons, 2010, pp. 89-153. Esto se relaciona con lo que es el resultado de la prueba en los procesos judiciales. En este sentido, una de las interrogantes que surge es si realmente iestamos preparados para aceptar las condenas judiciales en base a la probabilidad obtenida de la prueba? 
si los métodos utilizados por la prueba que pretenda calificarse de científica son fiables y la valoración relativa a la fiabilidad de sus datos, entendidos como los resultados o conclusiones a las que se arriba luego de producida o diligenciada la probanza correspondiente..$^{43}$

En ese sentido, resulta ilustrativa la exposición de Taruffo, quien expresa que: "Entre los múltiples problemas concernientes a las pruebas científicas uno de los más difíciles es la determinación de "qué ciencia" merece ser admitida y usada en los procesos judiciales. (...) es que la idea común de la ciencia como fuente de pruebas judiciales ha cambiado. Tradicionalmente, de hecho, el uso probatorio de la ciencia consistía esencialmente en pruebas periciales en los campos de la medicina, la química, la ingeniería y a veces la física y las matemáticas. En pocas palabras, sólo un número limitado de ciencias "duras" eran tomadas en cuenta. Todas las demás, excepto algunas materias "técnicas" como la mecánica o la construcción, quedaban al albur del sentido común o de la cultura media del juzgador. Hoy en día, el panorama de las ciencias que pueden ofrecer pruebas judiciales es completamente diferente. Por una parte, las ciencias duras tradicionales son cada vez más sofisticadas y especializadas: hablamos actualmente de genética, bioquímica, epidemiología, toxicología, etcétera. Por la otra, también las llamadas ciencias "blandas" o "sociales", como la psicología, la psiquiatría, la economía, la sociología, se consideran a menudo como posibles fuentes de prueba en el proceso civil". ${ }^{44}$

"Otro aspecto muy importante -agrega Taruffo- tiene que ver con la calidad y la fiabilidad de los datos e informaciones científicos que se presentan como medios de prueba. La distinción básica se traza entre "buena" ciencia y "mala" ciencia o ciencia "basura". El problema surge porque, en la experiencia práctica del uso de pruebas científicas, hay cientos de casos de errores, malentendidos y utilización de datos falsos o pocos fiables que pretenden ser científicamente correctos. (...) Incluso pruebas científicas que fueron consideradas absolutamente fiables, por ejemplo, la de las "huellas génicas o de ADN", están ahora bajo

43 O sea, estructuración de mecanismos fiables para la producción de la prueba (en el caso, aquella de tipo pericial y científico) que permita obtener buenos resultados o datos fiables. Según el diccionario de la lengua española, fiabilidad se define como "1. f. Cualidad de fiable. 2. f. Probabilidad de buen funcionamiento de algo" y fiable, por su parte, como "1. adj. Dicho de una persona: Que es digna de confianza. 2. adj. Que ofrece seguridad o buenos resultados. Mecanismo fiable. Método fiable. 3. adj. Creíble, fidedigno, sin error. Datos fiables.", REAL ACADEMIA ESPAÑOLA, Diccionario de la lengua española, vigésima segunda edición, [http://buscon.rae.es/drae/srv/search?val=fiabilidad] y [http://lema.rae. es/drae/srv/search?key=fiable], consultado el día 27/03/2014. 
escrutinio y su validez puede ser impugnada” (...) los datos científicos pueden ser poco fiables o insuficientes para apoyar una conclusión acerca de los hechos en litigio, las pruebas periciales pueden estar equivocadas o ser confusas, los peritos pueden no ser neutrales ni tener credibilidad (...), etcétera” ${ }^{45}$

Por ello Taruffo señala que no es casualidad que en el caso Daubert el Juez Blackmun -en la motivación de la mayoría de la Corte- estableciera cuatro criterios a los que se debería atener el Juez para admitir o excluir los medios de prueba científica presentados por las partes: “a) la controlabilidad y falseabilidad de la teoría científica o la técnica en la que se fundamenta la prueba; $b$ ) el porcentaje de error conocido o potencial, así como el cumplimiento de los estándares correspondientes a la técnica empleada; c) la publicación en revistas sometidas al control de expertos, de la teoría o la técnica en cuestión; d) la existencia de un consenso general de la comunidad científica interesada. Aunado a esto, el conocimiento científico en cuestión debe ser fit, es decir, directamente relevante y concretamente útil para decidir sobre los hechos del caso". 46

Se debe recordar que cuando las partes no le dan el carácter de arbitrador (i.e., perito decisorio), se está ante un perito cuyo dictamen no obliga al Juez. $\mathrm{Al}$ conocimiento especializado aplicado en la pericia concreta le debe seguir, por parte del magistrado, el análisis de sus requisitos de existencia, validez y eficacia probatoria. Por su parte, la apreciación final del dictamen se efectuará conforme a las pautas o reglas de la sana crítica. ${ }^{47}$

$45 \quad$ Ibídem., pp. 98 y 99.

$46 \quad$ Ibidem., p. 283.

47 Sobre la sana crítica como criterio general de valoración de la prueba en el Derecho procesal uruguayo, ver GAIERO GUADAGNA, Bruno J., SOBA BRACESCO, Ignacio M., “¿Cómo puede influir en la valoración de la prueba la abreviación estructural de los nuevos procesos Extra-CGP?", XV Jornadas Nacionales de Derecho Procesal, Montevideo, FCU, 2011, pp. 107-125. En Uruguay se analizó la aplicación de la sana crítica a "informes técnicos" en un caso en el que se debatió la existencia de contaminación por plomo derivada de la utilización de combustibles. En ese sentido, sostuvo el Tribunal de Apelaciones en lo Civil de $6^{\circ}$ Turno que: “...no resultó probado en autos que la contaminación del aire por plomo constituyera una conducta ilícita atribuible a la demandada ni que tal contaminación del aire hubiera afectado la salud humana. En cuanto a la ilicitud, primer elemento a analizar dentro de la configuración de un supuesto de responsabilidad civil, no se considera presente en la conducta desplegada por la demandada en la producción de gasolinas. A tales efectos, la prueba idónea está constituida por los informes de la Intendencia Municipal de Montevideo de fs. 2188 con respecto a los niveles de plomo obtenidos en el aire en las zonas de La Teja y La Blanqueada; el informe de la DINAMA y de la Intendencia Municipal de Montevideo de fs. 458 y 505/507; el informe ambiental Montevideo XXI de fs. 1582 y el informe del 
Efectivamente ello se puede apreciar si se analiza el citado caso Daubert vs Merrell Dow Pharmaceuticals, Inc., ya que en él todo el contexto problemático a nivel científico se trasladó al Derecho. Es que, aun cuando normalmente no se haga referencia al caso Daubert por parte de la doctrina del civil law, dicho precedente norteamericano puede ser considerado como el punto de partida para el estudio de los problemas que enfrenta -o que podría enfrentar- la prueba pericial ${ }^{48}$ en diferentes ordenamientos. ${ }^{49}$

Los criterios del caso Daubert pueden servir y ser aplicados a modo de 'filtro', como selección preliminar de pruebas científicas con el objetivo de admitir únicamente aquellas basadas en la ciencia 'válida'50, la cual luego, en la correspondiente valoración, tendrá en cuenta también esos factores para sopesar su eficacia y valor convictivo. El rol de gatekeeper a que se suele hacer referencia en la literatura anglosajona ${ }^{51}$, puede ser útil para comprender los desafíos que

Ing. Químico Rosario Martino obrante a fs. 1633/1635. Tales informes técnicos, valorados de conformidad con las reglas de la sana crítica (art. 140 CGP), conducen a formar convicción acerca de que no se ha acreditado el comportamiento ilícito que se atribuye a la demandada.". Uruguay, Tribunal de Apelaciones en lo Civil de $6^{\circ}$ Turno, sentencia ${ }^{\circ}$ 273/2004, del 3 de noviembre de 2004, Martínez -redactor-, Bossio, Hounie, en Revista La Justicia Uruguaya On Line: UY/JUR/247/2004. Ver también: sección jurisprudencia anotada, Revista Uruguaya de Derecho Procesal, 2/2005, Montevideo: FCU, pp. 475 y ss., en donde también se encuentra publicada la sentencia nº 237/2005, de 23 de noviembre de 2005, dictada por la Suprema Corte de Justicia en el caso de referencia, Gutiérrez, Parga R-, Van Rompaey, Rodríguez Caorsi, Troise (con comentario de PEREIRA CAMPOS, Santiago, GARDERES, Santiago, "Intereses difusos y defensa del medio ambiente (Inhibición o interdicción a ANCAP de producir y poner en el mercado gasolinas con plomo)", en Revista Uruguaya de Derecho Procesal, 2/2005, Montevideo, FCU, pp. 484-491).

48 De la consulta efectuada a la Base de Jurisprudencia Nacional en el mes de marzo de 2014, no se pudo acceder a ninguna sentencia que hubiese mencionado en su texto la palabra "Daubert" o la palabra "Merrell”. BASE DE JURISPRUDENCIA NACIONAL PÚBLICA - Poder Judicial de la República Oriental del Uruguay: [http://bjn.poderjudicial.gub.uy/BJNPUBLICA/ busquedaSimple.seam], consultado el día 27/03/2014.

49 Debe aclararse, siguiendo a TARUFFO, que en los sistemas del civil law el enfoque del problema es, en general, otro: "Si bien en Daubert el problema fue abordado en términos de la admisibilidad de las pruebas periciales, dado que en el sistema estadounidense el problema es sobre todo de selección de pruebas que pueden ser presentadas, en otros sistemas procesales el problema de las pruebas científicas tiene también otro aspecto: como se mencionó anteriormente, uno de los problemas más importantes que plantean las pruebas periciales es la valoración que el juez debe hacer de los resultados del trabajo del perito.". TARUFFO, Michele, La prueba, Madrid, Marcial Pons, 2008, p. 100.

$50 \quad$ Ibidem., pp. 99 y 283.

51 Sobre la tarea de gatekeeper que se le atribuye al juez, véase en especial: TARUFFO, Michele, Sobre las fronteras. Escritos sobre la justicia civil, Bogotá, Temis, 2006, p. 135. 
deben enfrentar los jueces para evitar que se cuele en el proceso la mala ciencia (junk science). Se aprecia, así, la necesidad de que exista algún tipo de control jurisdiccional relativo a la admisibilidad y, también, a la eficacia de la prueba pericial.

De ahí que se consideren adecuadas las previsiones legales contenidas en el ya citado art. 226 del Código General del Proceso de la República de Colombia. A saber: “...Todo dictamen debe ser claro, preciso, exhaustivo y detallado; en él se explicarán los exámenes, métodos, experimentos e investigaciones efectuadas, lo mismo que los fundamentos técnicos, científicos o artísticos de sus conclusiones. El dictamen suscrito por el perito deberá contener, como mínimo, las siguientes declaraciones e informaciones: 1. La identidad de quien rinde el dictamen y de quien participó en su elaboración. (...) 3. La profesión, oficio, arte o actividad especial ejercida por quien rinde el dictamen y de quien participó en su elaboración. Deberán anexarse los documentos idóneos que lo habilitan para su ejercicio, los títulos académicos y los documentos que certifiquen la respectiva experiencia profesional, técnica o artística. 4. La lista de publicaciones, relacionadas con la materia del peritaje, que el perito haya realizado en los últimos diez (10) años, si las tuviere. 5. La lista de casos en los que haya sido designado como perito o en los que haya participado en la elaboración de un dictamen pericial en los últimos cuatro (4) años. Dicha lista deberá incluir el juzgado o despacho en donde se presentó, el nombre de las partes, de los apoderados de las partes y la materia sobre la cual versó el dictamen. 6. Si ha sido designado en procesos anteriores o en curso por la misma parte o por el mismo apoderado de la parte, indicando el objeto del dictamen. (...) 8. Declarar si los exámenes, métodos, experimentos e investigaciones efectuados son diferentes respecto de los que ha utilizado en peritajes rendidos en anteriores procesos que versen sobre las mismas materias. En caso de que sea diferente, deberá explicar la justificación de la variación. 9. Declarar si los exámenes, métodos, experimentos e investigaciones efectuados son diferentes respecto de aquellos que utiliza en el ejercicio regular de su profesión u oficio. En caso de que sea diferente, deberá explicar la justificación de la variación. 10. Relacionar y adjuntar los documentos e información utilizados para la elaboración del dictamen.”.

También se consideran relevantes las pautas dadas por el art. 347 de la Ley de Enjuiciamiento Civil española 1/2000, cuando establece que las partes y sus defensores podrán pedir a los peritos, en especial: “...1 Exposición completa del dictamen (...) 2o Explicación del dictamen o de alguno o algunos de sus puntos, cuyo significado no se considerase suficientemente expresivo a los efectos de la prueba. $3^{\circ}$ Respuestas a preguntas y objeciones, sobre método, 
premisas, conclusiones y otros aspectos del dictamen. $4^{\circ}$ Respuestas a solicitudes de ampliación del dictamen a otros puntos conexos, por si pudiera llevarse a cabo en el mismo acto y a efectos, en cualquier caso, de conocer la opinión del perito sobre la posibilidad y utilidad de la ampliación, así como del plazo necesario para llevarla a cabo...".

De la mera lectura de las disposiciones parcialmente transcriptas, se advierte que se trata de regulaciones mucho más detalladas, y en cierto sentido más garantistas que aquellas previstas en el Código General del Proceso uruguayo o en el Código Procesal Civil Modelo para Iberoamérica, en tanto muchas de las exigencias mínimas referidas favorecen la transparencia y el control efectivo de la prueba. Es que se entiende, por ejemplo, que se debería señalar por el o los peritos la existencia de diferentes posiciones a nivel científico, para que los operadores jurídicos tengan más elementos al momento de apreciar el contexto en el cual se sitúan las conclusiones que se reflejan en un peritaje en particular.

A su vez, se debe tener presente que la actividad de valoración de acuerdo a las pautas o reglas de la sana crítica es diferente a la valoración científica que se realiza por el perito en el dictamen. La valoración del Juez se podría considerar un plus dentro del proceso respecto de la valoración científica del perito, ya que el Juez valora el dictamen y dicta sentencia, es él quien ejerce la función jurisdiccional, aun en el caso en que los peritos sean decisorios (donde el tribunal no tiene posibilidad de variar la medida de valor de la pericia, que es, en todo caso, 'plena' prueba ${ }^{52}$ ). La apreciación del dictamen por el Juez implica que su incapacidad técnica no se ve resuelta inmediatamente por los conocimientos volcados por el perito, hay un paso insoslayable que es la apreciación del magistrado guiado por las normas procesales que rigen la prueba. $^{53}$

52 BARRIOS DE ÁNGELIS, Dante, El proceso civil, Montevideo, Idea, 1989, p. 222.

53 Uruguay, Código General del Proceso, art. 184: “Los dictámenes de los peritos...serán apreciados por el tribunal de acuerdo con las reglas de la sana crítica (artículo 140), debiendo consignar en el fallo los motivos que tenga para apartarse de ellos". En muy similares términos, art. 172 del Código Procesal Civil Modelo para Iberoamérica. En otros ordenamientos también se prevé expresamente la valoración de la prueba pericial conforme el criterio de valoración de la sana crítica. Por ejemplo, véase el art. 348 de la Ley de Enjuiciamiento Civil $\mathrm{N}^{\circ} 1 / 2000$ española, de 7 de enero de 2000 y el art. 232 del Código General del Proceso de la República de Colombia, "APRECIACIÓN DEL DICTAMEN. El juez apreciará el dictamen de acuerdo con las reglas de la sana crítica, teniendo en cuenta la solidez, claridad, exhaustividad, precisión y calidad de sus fundamentos, la idoneidad del perito y su comportamiento en la audiencia, y las demás pruebas que obren en el proceso.". 
Quizás lo aquí expuesto sirva para contextualizar y considerar debidamente y en sus justos términos el valor real de los dictámenes periciales y para desmitificar muchos aspectos que rodean a este tipo de probanza, en las cuales se puede apreciar cierta 'confianza' respecto de lo que son sus resultados.

Normalmente se le asigna por parte de los operadores jurídicos la capacidad de producir certeza en cuanto a lo que se busca probar, cuando en puridad se obtiene tan sólo una visión científica de determinado hecho que quizás se deba asociar más a la probabilidad en sus resultados que a la propia noción de certeza. ${ }^{54}$ La probabilidad se presenta, cada vez más, como el grado máximo al que se puede aspirar en el conocimiento científico de los fenómenos fácticos. ${ }^{55}$

Con relación a esto, Döhring ${ }^{56}$ ha expresado que: "Tanto respecto de los pormenores, como respecto del resultado final, el perito tiene que indicar qué grado de certeza poseen sus comprobaciones", pero también señala que: "Expresiones tales como "probablemente", "muy probable" "sumamente probable", que sirven para determinar la seguridad, suelen ser empleadas con alcances bastantes diferentes por distintos peritos.".

Se debe distinguir, pues, los casos de peritos que buscan soslayar sus responsabilidades al momento de redactar sus conclusiones, de aquellos que

54 En ese sentido, SOZZO señala que: “...el establecimiento de causalidades y leyes explicativas como la principal actividad de la ciencia moderna ha sido sustituida por otra tarea mucho más limitada por cierto que es la averiguación de probabilidades. Otra falacia de la que parten -y que el derecho también absorbe sin cuestionamientos- es que la ciencia actúa linealmente y en forma apolítica. Por contrario como se encarga de demostrar Ulrich Beck la ciencia moderna, las ciencias denominadas duras, actúan políticamente. La ciencia se ve limitada por errores que no puede reconocer que ha cometido pues ello generaría una verdadera catástrofe política (Beck, Ulrich, 1998, p. 60). Para Beck, las ciencias naturales modernas "Se han convertido, pese a conservar exteriormente toda su objetividad, en una sucursal de la política, la ética, la economía y la jurisprudencia con el ropaje de los números" (Beck, Ulrich, 1998, pp. 90-91); los "números" de las mediciones, los umbrales de tolerancia y las hipótesis causales", las han colocado en la misma posición que las ciencias sociales: una posición política. Por otro lado, el derecho en este punto está basado en una tesis antigua respecto de las verdades científicas si se piensa que la ciencia posee el monopolio de la tarea de descubrir causalidades. La ciencia moderna solo realiza juicios probabilísticos.". Cfr. SOZZO, Gonzalo, "Riesgos del desarrollo y sistema de derecho de daños (hacia un derecho de daños pluralista)", en Revista La Ley Online, Cita Online: D1457/2010.

55 En realidad, por la complejidad del tema se exige una respuesta desde el punto de vista de la teoría del conocimiento. Es allí donde deben replicar estas y otras interrogantes.

56 DÖHRING, Erich, La investigación del estado de los hechos en el proceso. La prueba. Su práctica y apreciación, Buenos Aires, Ediciones jurídicas Europa - América, 1972, p. 253. 
no pueden llegar a un grado de certeza mayor por la insuficiencia de otros elementos probatorios relacionados con el caso concreto (esto es, por no contar - a modo de ejemplo- con elementos que le permitan obtener datos o informaciones relacionadas con la situación particular) o por el estado de la ciencia en un momento determinado.

Entiéndase bien, a veces es en virtud del estado de la ciencia que se trasladan dificultades al proceso (por ejemplo, porque no hay "certeza" científica sobre determinados enunciados fácticos ya que no hay "consensos" en la comunidad científica sobre la problemática planteada en el caso concreto ${ }^{57}$ ) y en otros casos, es el propio medio probatorio el que presenta deficiencias, ya sea por la forma en que se encuentra regulado (por ejemplo, por no haberse previsto en un determinado ordenamiento jurídico la posibilidad de recurrir a la opinión de juntas periciales, la limitación del número de peritos, la designación arbitraria de los organismos o personas a los que se puede pedir la prueba, el plazo o la limitación temporal en la realización del encargo, la falta de cualificación técnica o de actualización de los peritos, etc.), o por la forma en que ha sido utilizado en el caso concreto (piénsese en la hipótesis que no se hubiere acudido al organismo o al perito especializado que hubiere correspondido según la materia involucrada en el caso concreto).

Claramente, muchos de los problemas de la ciencia se trasladan al proceso, proyectando allí las dificultades que encuentra el conocimiento científico en un momento determinado para resolver los casos sometidos a decisión de los órganos judiciales.

Obviamente, se exige suma cautela en estos casos para apreciar cómo se ha producido la prueba y qué eficacia tiene la misma (más si las conclusiones a las que se arriban se basan en la probabilidad), para evitar el peligro de la satisfacción injusta de las pretensiones, que siempre se encuentra latente. Se reitera, el respeto al debido proceso y el ejercicio pleno del derecho de defensa resulta ineludible.

Nuevamente, el Juez deberá analizar las conclusiones de los peritos, su contexto de producción y cómo se justifican sus conclusiones. Denti -citado

57 Se presenta como interesante en ese sentido la regla 35.12 de las Civil Procedural Rules del Reino Unido que refiere a las discusiones entre expertos. Allí se prevé, entre otras cosas, que el tribunal puede, en cualquier momento, dirigir una discusión entre los expertos con el fin de exigir que estos identifiquen sus acuerdos y/o desacuerdos y de ser posible lleguen a una especie de consenso en sus opiniones. MINISTRY OF JUSTICE: Civil Procedural Rules - Part 35 Experts and Assessors: [http://www.justice.gov.uk/courts/procedure-rules/civil/rules/ part35], consultado el día 27/03/2014. 
por Parra- señala que el “...control de la peritación por parte del Juez expresa la necesidad de garantizar que el aporte al proceso de los conocimientos científicos suceda de tal manera que haga posible la comprensión y el consenso de los grupos sociales en los cuales y para los cuales el proceso se celebra". ${ }^{58}$ De esa forma, el análisis de la prueba científica sólo se podrá considerar completo si se asume el enorme desafío de considerar ciertas discusiones que se plantean a nivel de la teoría de la ciencia y del conocimiento. ${ }^{59}$

58 Cfr. PARRA QUIJANO, Jairo, Manual de derecho probatorio, Bogotá, Ediciones Librería del profesional, décimo tercera edición, 2002, p. 554.

59 La jurisprudencia uruguaya no ha recogido aún el análisis de fiabilidad de la prueba pericial de tipo científico que aquí se propugna. Su valoración de la prueba pericial se mantiene por carriles que se podrían denominar como más tradicionales. A modo de ejemplo, la Suprema Corte de Justicia ha expresado al respecto: "Cabe recordar que si bien es cierto que la adopción por el Tribunal de las conclusiones periciales no requiere en nuestro ordenamiento fundamentación ulterior, sí lo impone en cambio, el apartamiento (artículo 184 Código General del Proceso). Si el peritaje aparece fundado en principios técnicos inobjetables y no existe otra prueba que los desvirtúe, la sana crítica aconseja, frente a la imposibilidad de oponer argumentos científicos de mayor valor, aceptar las conclusiones de aquél. Para apartarse de sus conclusiones el Tribunal deberá fundarse en razones, que demuestren en forma objetiva o bien que no tiene fuerza de convicción suficiente, o que se han violado principios lógicos o máximas de experiencia o que existen en el proceso otras pruebas de mayor eficacia acerca de la verdad de los hechos controvertidos...". Uruguay, Suprema Corte de Justicia: sentencia n ${ }^{\circ}$ 56, de 20 de marzo de 2009, en Anuario de Derecho Civil Uruguayo, Tomo XL, Montevideo, FCU, caso 631, pp. 502 y 503; publicada además en Revista Uruguaya de Derecho Procesal, 1-2/2010, Montevideo, FCU, caso 947, p. 526. Ver también de la Suprema Corte de Justicia: sentencia ${ }^{\circ}$ 62, de 25 de marzo de 2009, en Revista Uruguaya de Derecho Procesal, 1-2/2009, Montevideo, FCU, caso 948, pp. 526-527. Más recientemente, la Suprema Corte de Justicia ha reiterado su posición respecto de la valoración del peritaje, en un caso en el que además se destacó lo siguiente: "Resulta evidente la trascendencia del peritaje en un litigio como el de autos ( $v . g r$. en el caso el perito era un Ingeniero; la reclamación de daños correspondía al incumplimiento atribuido a la Administración de Usinas y Trasmisiones Eléctricas - UTE por el aumento de la tensión eléctrica por encima de los límites tolerables), en el cual se discute la existencia de hechos para cuya apreciación se necesitan conocimientos científicos o técnicos especiales que, claro está, el juzgador no posee, lo cual marca claramente la procedencia de esta prueba en una hipótesis como la controvertida (art. 177 inc. 1 del C.G.P.).”. Uruguay, Suprema Corte de Justicia: sentencia n²532/2011, de 25 de julio de 2011. Su consulta, así como la de gran parte de la jurisprudencia uruguaya más reciente de los Tribunales de Apelaciones y de la Suprema Corte de Justicia se puede consultar En: BASE DE JURISPRUDENCIA NACIONAL PÚBLICA - Poder Judicial de la República Oriental del Uruguay: [http://bjn. poderjudicial.gub.uy/BJNPUBLICA/busquedaSimple.seam]. 
Todo ello debería ser explicitado en los peritajes y en las propias decisiones jurisdiccionales para facilitar el contralor de los restantes partícipes del proceso. ${ }^{60}-61$

\section{REFLEXIONES FINALES}

La ciencia -incorporada a los debates jurisdiccionales a través de la prueba científica, por ejemplo, de tipo pericial- es cada vez más trascendente para el Derecho.

El diligenciamiento de la prueba científica en el Proceso se debe producir en el marco de una regulación adecuada, la cual debe tener presente las particularidades que tiene el conocimiento científico. Precisamente, se requiere un mayor análisis y reflexión acerca de la propia regulación de la prueba pericial en el ordenamiento jurídico procesal, a efectos de determinar si la misma brinda un marco apropiado para la introducción -con ciertas garantías- del conocimiento científico en los procesos jurisdiccionales, sea estos de tipo individual o colectivo. Esta prueba resulta de utilidad en casos en los que se debe probar ciertos nexos de causalidad, la hipotética existencia de riesgos de desarrollo, la correcta aplicación del principio precautorio, etc.

La prueba científica, la prueba pericial, la prueba estadística, etc. se debe diligenciar respetando las garantías del debido proceso y el ejercicio pleno y eficaz del derecho de defensa. Las partes deben tener oportunidad de controlar la idoneidad de los peritos, los antecedentes de los mismos, la calidad de los estudios estadísticos (conociendo, por ejemplo, cómo se realizó la muestra o cómo se formaron las 'poblaciones' a los efectos de extrapolar resultados, qué protocolos de seguridad se siguieron, etc.), la fiabilidad de las conclusiones (aún cuando las mismas consistan en resultados basados en la probabilidad

60 En el caso de la prueba estadística (que en ciertos aspectos se presenta como cercana a la prueba científica) se debería especificar, por ejemplo, cómo se realizaron los muestreos, a qué tipo de poblaciones se pueden extrapolar las conclusiones estadísticas, quién realizó la estadística, qué grado de reconocimiento posee, etc. A su vez, se debería exigir un atento control del procedimiento probatorio al cual se recurra para diligenciar la prueba cuando se utilizan consultas a organizaciones no gubernamentales, instituciones educativas como universidades, integrantes individuales de la comunidad científica, etc.

${ }_{61}$ El problema será, una vez más, distinguir el déficit de fiabilidad de la prueba científica en el proceso con la falibilidad del conocimiento científico explicitado en el dictamen correspondiente, pues "...las vacilaciones a partir de un conocimiento falible son esperables, fundar sólo en ellas la incursión del Juez parece inconsistente, tanto como esperar una respuesta no-vacilante (...) fundada en el mismo cuerpo de conocimiento...”. Cfr. CAFFERA, Gerardo, "Los supuestos implícitos en la evaluación de responsabilidad profesional", en Anuario de Derecho Civil Uruguayo, Tomo XXXIV, Montevideo, FCU, p. 701. 
o en incertidumbres científicas irreductibles), el método empleado para la realización del dictamen, etc.

Aun cuando la valoración de la prueba de tipo científico se puede considerar ciertamente limitada, ya que los Jueces y también, normalmente, las partes no cuentan con elementos para apreciar o cuestionar la corrección de los métodos empleados o de los resultados obtenidos, sí se podrán controlar ciertos parámetros o elementos relacionados, por ejemplo, con la forma de producción de la prueba. Las pautas brindadas en el caso Daubert por parte de la Corte Suprema de los Estados Unidos pueden adoptarse como base o punto de partida para el control que debería ser ejercido por los Jueces respecto del conocimiento científico que se introduce en el proceso.

Las dificultades en la determinación y control de la fiabilidad del conocimiento extra-jurídico es una de las preocupaciones que se quieren dejar latentes con el presente trabajo. El Juez no tiene la cultura técnica o científica específica que sí tiene el perito, por eso es necesario que cuente con el experto para adquirir el conocimiento en pos de una optimización de su base cognoscitiva, evitando el peligro de la arbitrariedad y falta de racionalidad en el pronunciamiento judicial.

El abandono de la eficacia apriorística de los distintos medios probatorios (pregonada por la prueba tasada o del sistema de la tarifa legal), de la uniformidad de las decisiones jurisdiccionales, de la fijeza de las máximas de la experiencia y, correlativamente, la adopción de una teoría general de la prueba procesal, coherente y sistematizada, con reglas generales basadas en principios aplicables a todos los medios de prueba, así como la ubicación correcta de toda esta problemática dentro del campo más vasto de la teoría del conocimiento y, en definitiva, la utilización de las reglas de la sana crítica, hacen que el Juez pueda manejarse dentro de un ámbito de cierta libertad para la apreciación razonable - no arbitraria- de la prueba. ${ }^{62}$

El intento por obtener el conocimiento de tipo científico en el proceso jurisdiccional puede implicar el arrastre de los problemas (no necesariamente negativos) que se generan en el ámbito de la propia ciencia (por ejemplo, por la existencia de paradigmas, crisis de paradigmas, falta de consensos, 'parlamentarización' de la ciencia, etc.) al Proceso; lo cual hace necesario plantear desde el punto de vista crítico (y eventualmente, proyectivo) el análisis de la

62 GAIERO GUADAGNA, Bruno J., SOBA BRACESCO, Ignacio M., "La sana crítica y la motivación de las decisiones jurisdiccionales en materia probatoria", Revista Uruguaya de Derecho Procesal, 3-4/2010, Montevideo, FCU, pp. 845-859. 
regulación procesal del procedimiento probatorio en general y, en particular, de la prueba pericial. En ese sentido, se podría realizar -o, al menos, intentarun análisis o test de las reglas de derecho probatorio para determinar si a través de las mismas se permite la adecuada incursión en los aspectos extra-jurídicos mediante la producción de prueba de tipo científico.

Eventualmente, se podría diseñar institucionalmente la prueba pericial, haciéndola más dúctil o flexible - pero no por ello menos garantista- para que sea más sencillo el incorporar al Proceso el conocimiento técnico o científico de calidad. Al mismo tiempo, se deberían pautar exigencias mínimas para mejorar el control de la prueba pericial. Se entiende necesario propiciar la actualización y revisión de algunos mecanismos de control para la introducción del conocimiento científico a los procesos jurisdiccionales, exigiendo a su vez respecto de la prueba una motivación o fundamentación consistente, completa, precisa, crítica, controversial. La motivación de las decisiones jurisdiccionales en materia probatoria es una de las formas que existen en el ordenamiento jurídico para evitar las arbitrariedades y ejercer el control de las resoluciones ${ }^{63}$ en pos de una más efectiva tutela de los derechos sustanciales y una mayor transparencia. ${ }^{64}$

\section{1 de marzo de 2014 - Montevideo, Uruguay}

63 GARRIDO señala que: “...la seguridad del Derecho exige que los poderes públicos realicen actos de producción y aplicación de las normas de una manera no arbitraria. (...) donde reina la arbitrariedad, el poder representa una fuente permanente de inseguridad..." (Cfr. GARRIDO GÓMEZ, María Isabel, "La predecibilidad de las decisiones judiciales", en Revista Ius Et Praxis (online), Año 15, No 1, [http://www.scielo.cl/scielo.php?pid=S071800122009000100003\&script=sci_abstract], consultado el día 27/03/2014). Se podría aceptar, pues, la seguridad como estándar que se produce, o al cual se llega, si se minimiza la arbitrariedad en el sistema de decisiones jurisdiccionales. Evitar los excesos de poder hace a la propia conformación de un Estado de Derecho de calidad.

64 Debe señalarse que la manera a través de la cual los sistemas procesales modernos han tendido a evitar la arbitrariedad de los fallos es exigiendo la debida motivación de las resoluciones, y en materia probatoria ello no es la excepción (Cfr. entre muchos otros, TARUFFO, Michele, ANDRÉS IBÁÑEZ, Perfecto, CANDAU PÉREZ, Alfonso, Consideraciones sobre la prueba judicial, $2^{\text {a }}$ edición, Madrid: Fundación Coloquio Jurídico Europeo, 2010). Es que la motivación y la fundamentación de las sentencias constituyen una garantía para el 'debate procesal' (o 'diálogo procesal' entendido éste en sentido amplio). Es, a su vez, mediante la explicitación de los fundamentos y motivos que se permite que los sujetos que participan del proceso, así como los sujetos que estando fuera del proceso concreto también se ven involucrados en el examen crítico de las decisiones judiciales, realicen los correspondientes controles procesales y extraprocesales. El control del ejercicio de la función jurisdiccional permite evitar o reducir los márgenes de arbitrariedad en las decisiones. Así se posibilita el conocimiento de las razones que se tuvieron en cuenta por el tribunal para adoptar su decisión (así como la relevancia asignada a cada medio probatorio 


\section{REFERENCIAS}

ABAL OLIÚ, Alejandro. "Cuando debe tenerse por existente un hecho que integra el objeto de la prueba. Valoración de la prueba, presunciones simples y reglas sobre carga de la prueba”, en XV Jornadas Nacionales de Derecho Procesal (Mercedes, 2011), Montevideo, FCU, 2011, pp. 19-40.

ATIENZA, Manuel. El Derecho como argumentación, Barcelona, Editorial Ariel S.A., 2006.

AYER, A. J., "Posibilidad, probabilidad y casualidad", en CARNAP, Rudolf, MORGENSTERN, Oskar, WIENER, Norbert, et al: Matemáticas en las ciencias del comportamientos, traducción de Jesús Hernández, Madrid, Editorial Alianza Universidad, 1974.

BARRIOS DE ÁNGELIS, Dante, El proceso civil, Montevideo, Idea, 1989.

- Teoría del Proceso, segunda edición actualizada (reimpresión), MontevideoBuenos Aires, BdeF, 2005.

BERRO, Guido; DÁTTOLE, Antonio, OLIVERA, Hugo, "La peritación médicolegal y otros medios probatorios", IX Jornadas Nacionales de Derecho Procesal (Rivera-1997), Montevideo, Editorial Universidad, 1997, pp. 195-207.

BORRÀS PENTINAT, Susana, Los mecanismos de control de la aplicación y del cumplimiento de los tratados internacionales multilaterales de protección del medio ambiente, Tarragona, Universitat Rovira i Virgili, Departament de Dret Públic, 2007.

dentro del cúmulo que obra en el expediente). Los razonamientos y los motivos contribuyen a saber cómo el proceso resultó favorable o desfavorable (Cfr. GAIERO GUADAGNA, Bruno J., SOBA BRACESCO, Ignacio M., "La problemática de la apelación de los fundamentos de las sentencias: la parte expositiva ¿también agravia?”, en XIV Jornadas Nacionales de Derecho Procesal, Montevideo, FCU, 2009, pp. 239-254; SOBA BRACESCO, Ignacio M., "La fundamentación de las sentencias como garantía. Una forma de contribuir a la tutela jurisdiccional efectiva y a la predicción de las decisiones de los tribunales", en Revista La Ley Online, Cita Online: D17/2011). En Uruguay, la Suprema Corte de Justicia también lo ha destacado en sus fallos, así, por ejemplo, en sentencia n 2097/2011, de 27 de junio de 2011, se sostuvo -siguiendo a la doctrina nacional- que: "Sin duda, la motivación constituye la parte más importante de la sentencia, en la que el Juez expone los motivos o fundamentos en los que basa su decisión, es decir las razones que lo llevaron a adoptar una u otra solución en el conflicto que estaba llamado a resolver (...). Dicho requisito esencial del acto conclusivo de la causa define a la sentencia como un acto reflexivo y no discrecional de la voluntad autoritaria del magistrado, y permite controlar el modo en que los Jueces ejercen su poder jurisdiccional.". 
CAFFERA, Gerardo, "Los supuestos implícitos en la evaluación de responsabilidad profesional”, en Anuario de Derecho Civil Uruguayo, Tomo XXXIV, Montevideo, FCU, pp. 699-701.

CARDINAL, Fernando, "Algunas reflexiones sobre la valoración de la prueba pericial”, Revista Uruguaya de Derecho Procesal, 4/1996, Montevideo, FCU, pp. 641-645.

, KLETT, Selva, "El informe del asesor técnico de la parte: su naturaleza jurídica y valoración”, en IX Jornadas Nacionales de Derecho Procesal (Rivera-1997), Montevideo, Editorial Universidad, 1997, pp. 209-217.

\section{CORNELL UNIVERSITY LAW SCHOOL - LEGAL INFORMATION} INSTITUTE. Federal Rules of Evidence - Rule 702. Testimony by Expert Witnesses: [http://www.law.cornell.edu/rules/fre/rule_702].

CHALMERS, Alan F., ¿Qué es esa cosa llamada ciencia?, Madrid, Siglo XXI, decimosexta edición, 1994.

DAMASKA, Mirjan, Las caras de la justicia y el poder del Estado. Análisis comparado del proceso legal, Santiago, Editorial Jurídica de Chile, 2000.

DEVIS ECHANDÍA, Hernando, Teoría general de la prueba judicial, Tomos I y II, quinta edición, Buenos Aires, Víctor P. de Zavalía-Editor, 1981.

DÖHRING, Erich, La investigación del estado de los hechos en el proceso. La prueba. Su práctica y apreciación, Buenos Aires. Ediciones jurídicas Europa - América, 1972.

DONDI, Angelo, "Paradigmi processuali ed 'expert witness testimony' nel diritto statunitense”, Revista Trimestrale di Diritto e Procedura Civile, Milan, 1996, Dott. A. Giuffrè Editore, pp. 261-285.

FERRAJOLI, Luigi, Derechos y garantías. La ley del más débil, traducción de ANDRÉS IBAÑEZ, Perfecto, GREPPI, Andrea, cuarta edición, Madrid, Trotta, 2004.

, "El derecho como sistema de garantías", en Revista Uruguaya de Derecho Procesal, 2/1999, Montevideo, FCU.

FERRATER MORA, José: Diccionario de filosofía abreviado (texto preparado por GARCÍA BELSUNCE, Eduardo, DE OLASO, Ezequiel), Barcelona, Edhasa-Sudamericana, vigésima reimpresión, 1993.

GAIERO GUADAGNA, Bruno, SOBA BRACESCO, Ignacio M., "La problemática de la apelación de los fundamentos de las sentencias: la parte 
expositiva ¿también agravia?”, XIV Jornadas Nacionales de Derecho Procesal, Montevideo, FCU, 2009, pp. 239-254.

, "La sana crítica y la motivación de las decisiones jurisdiccionales en materia probatoria”, Revista Uruguaya de Derecho Procesal, 3-4/2010, Montevideo, FCU, pp. 845-859.

, ¿Cómo puede influir en la valoración de la prueba la abreviación estructural de los nuevos procesos Extra-CGP?", XV Jornadas Nacionales de Derecho Procesal, Montevideo, FCU, 2011, pp. 107-125

GARDERES, Santiago, VALENTÍN, Gabriel con la colaboración de DÍAZ, Soledad: Código del Proceso Penal. Comentado, Montevideo-Buenos Aires, La Ley Uruguay, 2012.

GARRIDO GÓMEZ, María Isabel, "La predecibilidad de las decisiones judiciales", en Revista Ius Et Praxis (online), Año 15, № 1, [http://www.scielo.cl/ scielo.php?pid=S0718-00122009000100003\&script=sci_abstract.].

GELSI BIDART, Adolfo, "Significación de la pericia como instituto procesal", Revista Judicatura, № 33, Montevideo, 1992.

HARVARD LAW REVIEW, “Admitting doubt: a new standard for scientific evidence", 123 Harv. L. Rev. 2021 (2010). [ h t t p : / / w w w . harvardlawreview.org/media/pdf/vol123_admitting_doubt.pdf].

INSTITUTO IBEROAMERICANO DE DERECHO PROCESAL, "Código Modelo de Procesos Colectivos para Iberoamérica", XXVI Congreso Colombiano de Derecho Procesal, Bogotá, Universidad Libre, 2005, pp. 10951117.

KEMELMAJER DE CARLUCCI, Aida, "La seguridad jurídica", en La seguridad jurídica como dato para la decisión empresaria, separata de la Revista del Derecho Comercial y de las Obligaciones, edición especial patrocinada por la Fundación Konrad Adenauer, Depalma, Abril-Junio 1998.

KUHN, Thomas S.: El camino desde la estructura. Ensayos filosóficos 1970-1993, CONANT, James y HAUGELAND, John (compiladores), Barcelona, Paidós, 2002.

LANDONI SOSA, Ángel, "La prueba pericial con especial referencia al proceso civil", IX Jornadas Nacionales de Derecho Procesal (Rivera-1997), Montevideo, Editorial Universidad, 1997, pp. 219-234. (director); GOMES, Fernando; VALENTÍN, Gabriel; GARDERES, Santiago y GONZÁLEZ, María Eugenia, Código General del Proceso. 
Comentado, anotado, con jurisprudencia, Vol. 1, Montevideo-Buenos Aires, BdeF, 2002.

, Código General del Proceso. Comentado, anotado, con jurisprudencia, Vol. 2 A, Montevideo-Buenos Aires. BdeF, 2003.

MARIÑO LÓPEZ, Andrés: "La transformación de la obligación de informar al consumidor. Incidencia del paradigma de la precaución en el derecho del consumo”, en Revista La Ley Online, Cita Online: D3444/2009.

, "Bases del Derecho de daños al medio ambiente. Aportes para la construcción de acuerdos regionales en América Latina", en Anuario de Derecho Civil Uruguayo, Tomo XXXVII, Montevideo, FCU, pp. 647-660.

, Los fundamentos de la responsabilidad contractual, Montevideo, Carlos Álvarez Editor, 2005.

MINISTRY OF JUSTICE, Civil Procedural Rules - Part 35 Experts and Assessors: [http://www.justice.gov.uk/courts/procedure-rules/civil/rules/ part35].

MIRANDE, Santiago, "Precaver el desarrollo de lo desconocido. Riesgo de desarrollo, información y precaución en el Derecho Uruguayo.", en Revista La Ley Online, Cita Online: D3433/2009.

MONTERO AROCA, Juan, La prueba en el proceso civil, quinta edición, Pamplona, Thomson Civitas, 2007.

MONTORO BALLESTEROS, Alberto, "La aleatoriedad en el derecho y el problema de la justicia”, en Anales de Derecho, Murcia: Universidad de Murcia, Número 23, 2005, publicado En: http://revistas.um.es/analesderecho/index.

MOORE, Michael S., Causalidad y responsabilidad. Un ensayo sobre derecho, moral y metafísica, Madrid, Marcial Pons, 2011.

MÜLLER MÉNDEZ, Enrique Javier, "Los principios rectores del derecho ambiental. El principio precautorio y su relación con el principio de prevención”, en Revista La Ley Online, Cita Online: D3434/2009.

MÜlLER, Enrique C., "La prueba del daño ecológico", en Revista La Ley Online, Cita Online: D2676/2010.

PARRA QUIJANO, Jairo, Manual de Derecho Probatorio, decimotercera edición, ampliada y actualizada, Bogotá, Librería del Profesional, 2002.

PEREIRA CAMPOS, Santiago, GARDERES, Santiago, "Intereses difusos y defensa del medio ambiente (Inhibición o interdicción a ANCAP de producir y poner en el mercado gasolinas con plomo)", en Revista Uruguaya de Derecho Procesal, 2/2005, Montevideo, FCU, pp. 484-491. 
PLADA, Marcelo, “¿Hacia un derecho de daños polifuncional?”, en Revista La Ley Online, Cita Online: D2940/2009.

SALVADOR CODERCH, Pablo y RUBÍ PUIG, Antoni, "Riesgos de desarrollo y evaluación judicial del carácter científico de dictámenes periciales”, en Revista InDret, 1/2008, Barcelona, 2008, [http://www.indret.com/ pdf/519_es.pdf].

SOBA BRACESCO, Ignacio M., "La prueba pericial y el informe del asesor de parte en el proceso contencioso administrativo de anulación", XVI Jornadas Nacionales de Derecho Procesal (Paysandú-2013), Montevideo, Mastergraf, 2013, pp. 103-118.

, "La introducción del conocimiento científico al Proceso -con énfasis en los denominados procesos de daños-", Revista La Ley Uruguay, Año VI, $\mathrm{N}^{\circ}$ 1, Montevideo-Buenos Aires, La Ley Uruguay, 2013, pp. 29-50.

"La responsabilidad de los peritos por su actividad en el proceso: ¿una hipótesis de responsabilidad del Estado?", Revista Crítica de Derecho Privado, No 9, Montevideo-Buenos Aires, La Ley Uruguay, 2012, pp. 695-718.

, "La fundamentación de las sentencias como garantía. Una forma de contribuir a la tutela jurisdiccional efectiva y a la predicción de las decisiones de los tribunales", en Revista La Ley Online, Cita Online: D17/2011.

SOZZO, Gonzalo, "Riesgos del desarrollo y sistema de derecho de daños (hacia un derecho de daños pluralista)", en Revista La Ley Online, Cita Online: D1457/2010.

BERROS, María Valeria, "Una agenda para el principio precautorio", en Revista La Ley Online, Cita Online: D3440/2009 (publicado también en Revista Crítica de Derecho Privado, n 6, Montevideo-Buenos Aires: La Ley Uruguay, 2009, pp. 763-793).

TARUFFO, Michele, La motivación de la sentencia civil, Madrid, Trotta, 2011.

, Simplemente la verdad. El juez y la construcción de los hechos, Madrid, Marcial Pons, 2010.

_, La prueba. Madrid, Marcial Pons, 2008.

, El proceso civil adversarial en la experiencia americana, Bogotá, Temis, 2008.

, La prueba de los hechos, Madrid, Trotta, 2005.

, Sobre las fronteras. Escritos sobre la justicia civil, Bogotá, Temis, 2006. 
, "Conocimiento científico y estándares de prueba judicial" [versión electrónica], Boletín Mexicano de Derecho Comparado, nueva serie, año XXXVIII, núm. 114, pp. 1285-1312.

, "Probabilidad y prueba judicial", XXVI Congreso Colombiano de Derecho Procesal, Universidad Libre, Bogotá, 2005, pp. 1077-1091.

TARUFFO, Michele; ANDRÉS IBÁÑEZ, Perfecto, CANDAU PÉREZ, Alfonso, Consideraciones sobre la prueba judicial, segunda edición, Madrid, Fundación Coloquio Jurídico Europeo, 2010.

VARELA-MÉNDEZ, Edgar J., "De los honorarios de los peritos", en Revista Judicatura, № 33, Montevideo, 1992, pp. 77-87.

VESCOVI, Enrique (director), DE HEGEDUS, Margarita, KLETT, Selva, CARDINAL, Fernando, SIMÓN, Luis María, PEREIRA CAMPOS, Santiago, Código General del Proceso. Comentado, anotado y concordado, Tomo 5, Buenos Aires: Ábaco, 1998.

WALTER, Gerhard, Libre apreciación de la prueba, versión castellana, Bogotá, Temis, 1985.

WITTHAUS, Rodolfo, Prueba pericial, Buenos Aires, Editorial Universidad, 1991.

ZAGREBELSKY, Gustavo, El derecho dúctil, quinta edición, Madrid, Trotta, 2003. 